UNIVERSIDADE DE SÃo PAULO

INSTITUTO DE QUÍMICA DE SÃo CARLOS

\title{
EFEITO DA TEMPERATURA NA ELETRO-OXIDAÇÃO OSCILATÓRIA DE ÁCIDO FÓRMICO SOBRE PLATINA: EXPERIMENTOS E SIMULAÇÕES
}

Dissertação apresentada no Instituto de Química de São Carlos para obtenção do título de Mestre em Ciências, Físico-Química.

RAPHAEL NAGAO DE SOUSA

PROF. DR. HAMILTON VARELA (ORIENTADOR) 
"Aos meus pais e irmão por tudo ..." 


\section{AgRADECIMENTOS}

Ao amigo e orientador Hamilton, por ter ido além.

Aos amigos de trabalho e a todos os funcionários, os quais foram imprescindíveis para a execução desse trabalho.

Aos professores, Ernesto Gonzalez e Markus Eiswirth pelo apoio.

À minha companheira de todas as horas Adriana, sem você tudo seria mais difícil!

À minha família, pelo incentivo incondicional.

À minha segunda família, república Fiote de Bordoké e agregados, pelos valiosos momentos de descontração.

À USP e ao IQSC pelo ambiente intelectual propício para o desenvolvimento da minha formação profissional e pessoal.

À FAPESP pelo apoio financeiro, processo (MS) 06/04636-3. 
"This is not the end. It is not even the beginning of the end. But it is, perhaps, the end of the beginning."

Winston Churchill 


\section{SUMÁRIO}

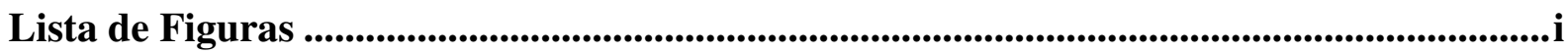

Lista de Tabelas ......................................................................................................................................iii

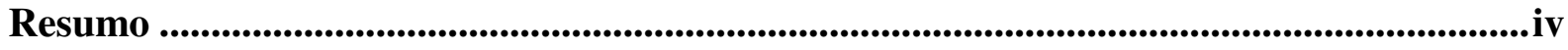

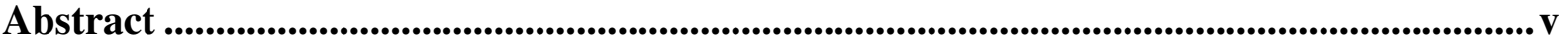

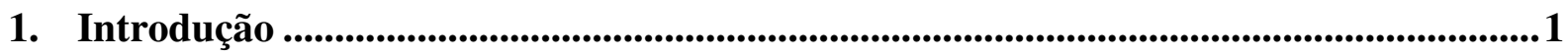

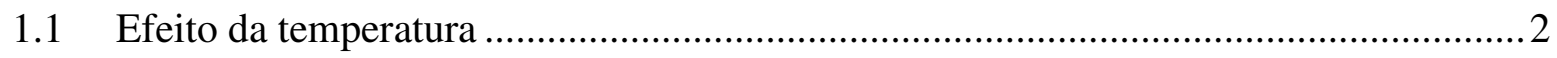

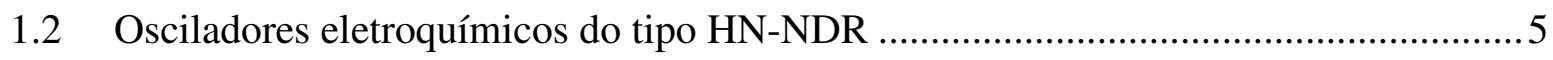

1.3 Eletro-oxidação de ácido fórmico sobre platina.................................................... 11

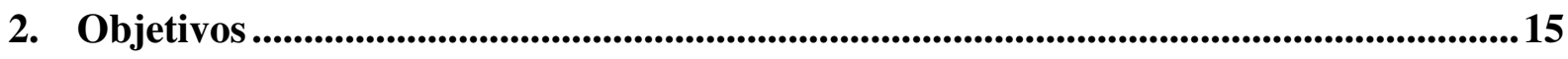

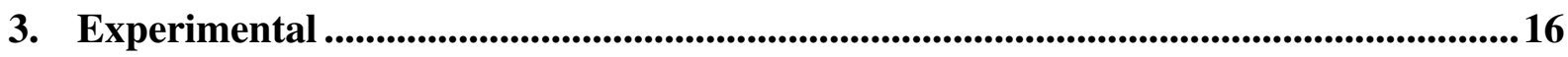

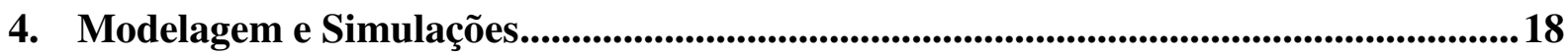

5. Resultados e Discussões ...............................................................................................30

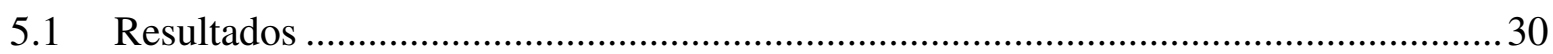

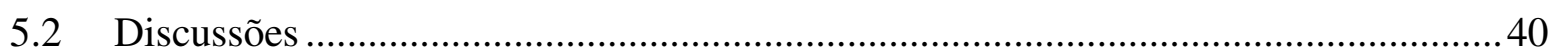

5.2.1 (Sobre)compensação de temperatura no período oscilatório............................... 40

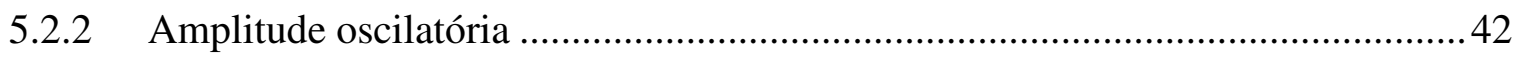

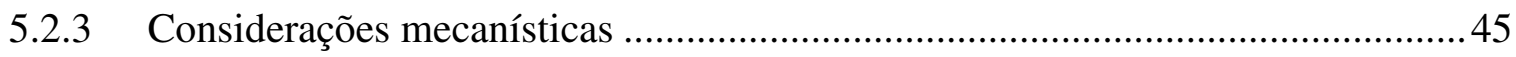

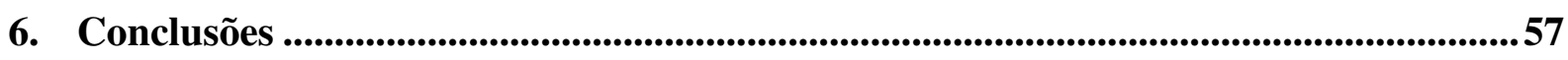

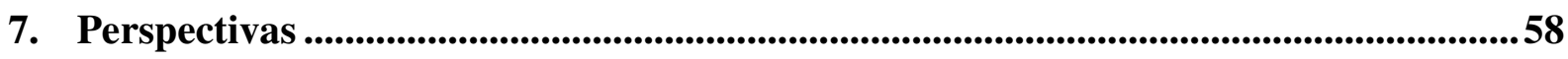

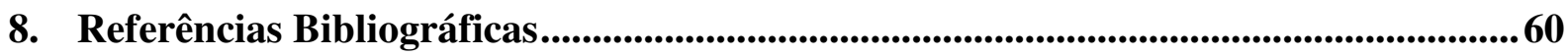

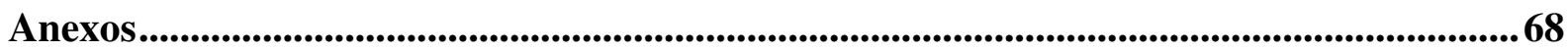




\section{LiSTA DE Figuras}

Figura 1: Circuito equivalente simplificado para a célula eletroquímica.

Figura 2: Simulações obtidas a partir do modelo genérico para sistemas do tipo HN-NDR proposto por Krischer et al. ${ }^{[7]}$. (a) curva estacionária em forma de " $\mathrm{N}$ ", (b) isoterma de adsorção da espécie "bloqueante" e (c) curva estacionária (azul) resultante de (a) + (b).

Figura 3: Esquema generalizado da interação entre os ciclos de retro-alimentação positivo e negativo responsáveis pelas oscilações observadas na reação de eletro-oxidação de moléculas orgânicas pequenas ${ }^{[8]}$

Figura 4: Mecanismo geral da eletro-oxidação de ácido fórmico (EAF) sobre platina policristalina.

Figura 5: Voltametria cíclica de platina policristalina em ácido sulfúrico obtido à $\mathrm{dU} / \mathrm{dt}=0,05$ $\mathrm{V} \mathrm{s}^{-1} \cdot\left[\mathrm{H}_{2} \mathrm{SO}_{4}\right]=0,1 \mathrm{~mol} \mathrm{~L}^{-1}$ e $\mathrm{T}=25^{\circ} \mathrm{C}$.

Figura 6: Simulações obtidas a partir do modelo proposto durante a EAF sobre platina para $\mathrm{dU} / \mathrm{dt}=0,01 \mathrm{~V} \mathrm{~s}^{-1}$ e $\mathrm{T}=25^{\circ} \mathrm{C}$. (a) varredura potenciodinâmica positiva, (b) isotermas de adsorção de $\mathrm{CO}_{\mathrm{L}}$ (preto), $\mathrm{HCOO}_{\mathrm{ad}}$ (vermelho) e $\mathrm{OH}_{\mathrm{ad}}$ (azul) e (c) contribuição de $\mathrm{j}_{\mathrm{i}}$ em $\mathrm{j}_{\mathrm{t}}$. A região da NDR apresenta-se como uma faixa rachurada. Parâmetros: $\mathrm{k}_{1}=2,0.10^{3} \mathrm{~L} \mathrm{~mol}^{-1} \mathrm{~s}^{-1}$, $\mathrm{k}_{2}=5,0.10^{2} \mathrm{~s}^{-1}, \mathrm{k}_{3}=0,8 \cdot 10^{2} \mathrm{~L} \mathrm{~mol}^{-1} \mathrm{~s}^{-1}, \mathrm{k}_{4}=0,6 \cdot 10^{-2} \mathrm{~L} \mathrm{~mol}^{-1} \mathrm{~s}^{-1}, \mathrm{k}_{-4}=2,0.10^{5} \mathrm{~s}^{-1}$.

Figura 7: Simulações obtidas a partir do modelo proposto durante a EAF sobre platina para $\mathrm{j}_{\mathrm{t}}$ $=1,0 \mathrm{~mA} \mathrm{~cm}^{-2} \mathrm{e} \mathrm{T}=25^{\circ} \mathrm{C}$. Séries temporais de (a) $\varphi_{\mathrm{DL}}$, (b) $\theta_{\mathrm{COL}}$, (c) $\theta_{\mathrm{HCOO}}$ e (d) $\theta_{\mathrm{OH}}$.

Parâmetros: $\mathrm{k}_{1}=3,0.10^{3} \mathrm{~L} \mathrm{~mol}^{-1} \mathrm{~s}^{-1}, \mathrm{k}_{2}=4,0.10^{2} \mathrm{~s}^{-1}, \mathrm{k}_{3}=1,0.10^{2} \mathrm{~L} \mathrm{~mol}^{-1} \mathrm{~s}^{-1}, \mathrm{k}_{4}=3,0.10^{-2} \mathrm{~L}$ $\mathrm{mol}^{-1} \mathrm{~s}^{-1}, \mathrm{k}_{-4}=3,0.10^{5} \mathrm{~s}^{-1}$

Figura 8: Esquema ilustrativo da (a) bifurcação de Hopf subcrítica e (b) bifurcação homoclínica.

Figura 9: Voltamogramas cíclicos durante a EAF sobre platina policristalina à $\mathrm{dU} / \mathrm{dt}=5 \mathrm{mV}$ $\mathrm{s}^{-1}$ em diferentes temperaturas. $\left[\mathrm{H}_{2} \mathrm{SO}_{4}\right]=0,1 \mathrm{~mol} \mathrm{~L}^{-1}$ e $[\mathrm{HCOOH}]=0,6 \mathrm{~mol} \mathrm{~L}^{-1}$. 30

Figura 10: Energias de ativação aparente em diferentes potenciais. Os valores foram obtidos a partir da varredura positiva nos voltamogramas cíclicos, vide Figura 9. 
Figura 11: Oscilações de potencial durante a EAF sobre Pt policristalina em controle galvanodinâmico $\left(\mathrm{dI} / \mathrm{dt}=5 \mu \mathrm{A} \mathrm{s}^{-1}\right)$ sob diferentes temperaturas. $\left[\mathrm{H}_{2} \mathrm{SO}_{4}\right]=0,1 \mathrm{~mol} \mathrm{~L}^{-1} \mathrm{e}$ $[\mathrm{HCOOH}]=0,6 \mathrm{~mol} \mathrm{~L}^{-1}$

Figura 12: Séries temporais de potencial durante a EAF sobre platina policristalina em diferentes temperaturas com $\mathrm{I}_{\mathrm{N}}^{\mathrm{T}}=0,33 .\left[\mathrm{H}_{2} \mathrm{SO}_{4}\right]=0,1 \mathrm{~mol} \mathrm{~L}^{-1}$ e $[\mathrm{HCOOH}]=0,6 \mathrm{~mol} \mathrm{~L}^{-1} \ldots .34$

Figura 13: Séries temporais de potencial durante a EAF sobre platina policristalina em diferentes temperaturas com $\mathrm{I}_{\mathrm{N}}^{\mathrm{T}}=0,83 .\left[\mathrm{H}_{2} \mathrm{SO}_{4}\right]=0,1 \mathrm{~mol} \mathrm{~L}^{-1}$ e $[\mathrm{HCOOH}]=0,6 \mathrm{~mol} \mathrm{~L}^{-1} \ldots .35$

Figura 14: (a) Período e (b) amplitude (normalizada em $\mathrm{A}^{\mathrm{T}}-\mathrm{A}^{5^{\circ} \mathrm{C}} / \mathrm{V}$ vs. RHE) oscilatória em função da temperatura para diferentes correntes normalizadas durante a EAF sobre platina policristalina.

Figura 15: Espectros de freqüências simulados a partir do modelo proposto durante a EAF sobre platina, sob regime (a) galvanostático e (b) potenciostático. Parâmetros: $\mathrm{k}_{1}=3,0.10^{3} \mathrm{~L}$ $\mathrm{mol}^{-1} \mathrm{~s}^{-1}, \mathrm{k}_{2}=4,0.10^{2} \mathrm{~s}^{-1}, \mathrm{k}_{3}=1,0.10^{2} \mathrm{~L} \mathrm{~mol}^{-1} \mathrm{~s}^{-1}, \mathrm{k}_{4}=3,0.10^{-2} \mathrm{~L} \mathrm{~mol}^{-1} \mathrm{~s}^{-1}, \mathrm{k}_{-4}=3,0.10^{5} \mathrm{~s}^{-1} \ldots 38$

Figura 16: Esquema ilustrativo das oscilações de potencial dividido em três etapas $1 \rightarrow 2,2$ $\rightarrow 3$ e $3 \rightarrow 4$.

Figura 17: Simulações obtidas a partir do modelo proposto durante a EAF sobre platina para $\mathrm{dI} / \mathrm{dt}=5 \mu \mathrm{A} \mathrm{s}^{-1}$ e $\mathrm{T}=25^{\circ} \mathrm{C}$. (a) variação do recobrimento médio $\theta^{\mathrm{m}}$ de $\mathrm{CO}_{\mathrm{L}}$ (preto), $\mathrm{CO}_{\mathrm{B}}$ (verde), $\mathrm{HCOO}_{\mathrm{ad}}$ (vermelho), $\mathrm{OH}_{\mathrm{ad}}$ (azul). (b) variação do recobrimento médio de sítios livres, $\theta_{\mathrm{V}}{ }^{\mathrm{m}}$ (preto) e velocidade média da reação $(\mathrm{r} 2), \mathrm{v}_{2}{ }^{\mathrm{m}}$ (vermelho). Parâmetros: $\mathrm{k}_{1}=1,0.10^{3}$ $\mathrm{L} \mathrm{mol}^{-1} \mathrm{~s}^{-1}, \mathrm{k}_{2}=1,1.10^{2} \mathrm{~s}^{-1}, \mathrm{k}_{3}=1,0.10^{2} \mathrm{~L} \mathrm{~mol}^{-1} \mathrm{~s}^{-1}, \mathrm{k}_{4}=3,0.10^{-2} \mathrm{~L} \mathrm{~mol}^{-1} \mathrm{~s}^{-1}, \mathrm{k}_{-4}=2,0.10^{5} \mathrm{~s}^{-1}$. 


\section{LISTA DE TABELAS}

Tabela I: Lista de parâmetros do modelo proposto.

Tabela II: Valores de $q_{10}$ obtidos para diferentes intervalos de temperatura e correntes aplicadas.

Tabela III: Energia de ativação aparente durante a EOM em diversos modos de operação ${ }^{[73]}$. 


\section{RESUMO}

Ritmos biológicos são regulados por mecanismos homeostáticos que asseguram a confiabilidade funcional do relógio fisiológico independentemente de mudanças de temperatura no ambiente. Compensação de temperatura, ou a independência do período oscilatório em relação à temperatura, é conhecida por exercer um papel central em muitos ritmos biológicos, mas um fenômeno raro em osciladores químicos. Estudou-se nessa dissertação a influência da temperatura na dinâmica oscilatória durante a oxidação catalítica de ácido fórmico sobre eletrodo de platina policristalina. Os experimentos foram conduzidos em cinco temperaturas diferentes de 5 à $25^{\circ} \mathrm{C}$, e as oscilações foram estudadas sob controle galvanostático. Resultados experimentais foram comparados a um novo modelo proposto para a eletro-oxidação de ácido fórmico, considerando formato como intermediário ativo e a desidrogenação da água em altos potenciais. Sob condições oscilatórias apenas comportamento anti-Arrhenius foi observado. Sobre-compensação com coeficiente de temperatura $\left(q_{10}\right.$, definido como a razão entre a constante de velocidade à temperatura $T+10$ ${ }^{\circ} \mathrm{C}$ e em $\left.T\right)<1$ é achada para a maioria dos casos, exceto em altas correntes aplicadas onde compensação de temperatura, $q_{10} \sim 1$ predomina. O comportamento do período e amplitude resulta de uma combinação complexa entre a temperatura e corrente aplicada ou, equivalentemente, a distância do equilíbrio termodinâmico. Altas energias de ativação aparente foram obtidas em condições voltamétricas, não-oscilatórias, as quais implicam que o comportamento anti-Arrhenius observado sob regime oscilatório resulta de um acoplamento entre as rotas reacionais em vez de uma fraca dependência da temperatura nas etapas elementares. Mecanisticamente, os experimentos e o modelo matemático sugerem que o período em regime de (sobre)compensação de temperatura durante a eletro-oxidação de ácido fórmico sobre platina é governado pelo acoplamento entre as taxas reacionais de formação/remoção de monóxido de carbono e formato em condições oscilatórias. 


\begin{abstract}
Biological rhythms are regulated by homeostatic mechanisms that assure that physiological clocks function reliably independent of temperature changes in the environment. Temperature compensation, i.e. the independence of the oscillatory period on temperature, is known to play a central role in many biological rhythms, but it is rather rare in chemical oscillators. It was studied in this master thesis the influence of temperature on the oscillatory dynamics during the catalytic oxidation of formic acid on a polycrystalline platinum electrode. The experiments are performed at five temperatures from 5 to $25^{\circ} \mathrm{C}$, and the oscillations studied under galvanostatic control. Experimental results are compared to a new model proposed for formic acid electro-oxidation, which includes formate as an active intermediate and water dehydrogenation at high potentials. Under oscillatory conditions only non-Arrhenius behavior is observed. Over-compensation with temperature coefficient $\left(q_{10}\right.$, defined as the ratio between the rate constants at temperature $T+10{ }^{\circ} \mathrm{C}$ and at $\left.T\right)<1$ is found in most cases, except that temperature compensation with $q_{10} \sim 1$ predominates at high applied currents. The behavior of the period and the amplitude result from a complex interplay between temperature and applied current or, equivalently, the distance from thermodynamic equilibrium. High, positive apparent activation energies were obtained under voltammetric, non-oscillatory conditions, which implies that the non-Arrhenius behavior observed under oscillatory conditions results from the interplay among reaction steps rather than from a weak temperature dependence of the individual steps. Mechanistically, the experiments and the mathematical model suggest that the period in temperature (over)compensation regime during electro-oxidation of formic acid at platinum is governed by the coupling among the reaction rates of formation/removal of carbon monoxide and formate coverage in oscillatory conditions.
\end{abstract}




\section{INTRODUÇÃo}

O estudo da formação espontânea de padrões auto-organizados em sistemas de reação/transporte tem se tornado uma área de pesquisa ativa nas últimas duas décadas. Comportamento complexo nesses sistemas emerge em condições afastadas do equilíbrio termodinâmico e resulta do acoplamento entre a dinâmica temporal não-linear (multi-estável, excitatória ou oscilatória) e propriedades de transporte de massa (difusão ou migração). Possui caráter interdisciplinar sendo encontrada em diversos campos de pesquisa, incluindo química, física, biologia, ciência dos materiais e geologia ${ }^{[1]}$. Exemplos físico-químicos são encontrados em sistemas homogêneos como na celebrada reação de Belousov-Zhabotinsky ${ }^{[2]}$ e heterogêneos, tanto na interface sólido/gás ${ }^{[3]}$, quanto na interface sólido/líquido ${ }^{[4-7]}$.

O estudo do fenômeno auto-organizado em eletroquímica torna-se atrativo devido à facilidade de manipulação dos parâmetros elétricos e pela rica dinâmica temporal encontrada durante a eletro-oxidação de moléculas orgânicas pequenas. Sob o ponto de vista fundamental, auto-organização espaço-temporal em eletrocatálise apresenta-se como um sistema-modelo ideal no estudo de fenômenos emergentes e na elucidação de mecanismos reacionais ${ }^{[8]}$. Entretanto, o comportamento mecanístico resultante da quebra de simetria espaço-temporal ainda permanece obscuro. Atenção da comunidade científica foi dada especialmente na caracterização do sistema por meio de técnicas de análise temporal em dinâmica não-linear. Considerando a temperatura como parâmetro fundamental em termodinâmica e cinética química e, portanto, atuando um papel decisivo nas etapas elementares de reação, a presente dissertação tem como objetivo central o estudo detalhado da influência da temperatura na dinâmica oscilatória observada durante a eletro-oxidação de ácido fórmico sobre platina policristalina. A identificação do mecanismo reacional regente será embasada em observações experimentais e simulações numéricas. 


\subsection{EFEITO DA TEMPERATURA}

A temperatura é um parâmetro que exerce papel fundamental em reações químicas. A dependência das taxas reacionais com relação à temperatura pode ser expressa pelo coeficiente de temperatura, $Q_{10}^{[9,10]}$, o qual é definido como a razão entre a constante de velocidade $k$ na temperatura $T+10^{\circ} \mathrm{C}$ e em $T$,

$$
Q_{10}=\frac{k_{T+10}}{k_{T}}
$$

Para um intervalo de temperatura arbitrário, pode-se escrever,

$$
q_{10}=\left(\frac{k_{T_{2}}}{k_{T_{1}}}\right)^{\frac{10}{\left(T_{2}-T_{1}\right)}}
$$

onde $q_{10}$ é o coeficiente de temperatura $Q_{10}$ no intervalo de temperatura entre $T_{1}$ e $T_{2}$. A energia de ativação obtida pela equação de Arrhenius pode ser escrita em termos de $q_{10}$ como,

$$
E_{a}=R\left(\frac{T_{1} T_{2}}{10}\right) \ln q_{10}
$$

onde $R$ é a constante dos gases.

De regra geral, a maioria das reações químicas e bioquímicas tem coeficientes de temperatura em torno de 2 à $4^{[9]}$. Apesar da forte dependência das taxas reacionais com a temperatura, sistemas acoplados como redes de reações bioquímicas, podem ser independentes da temperatura sobre um considerável intervalo de temperatura, o que 
corresponde à $Q_{10}$ ou $q_{10}$ próximo de 1 . Esta invariância do período oscilatório é conhecida como compensação de temperatura ${ }^{[11]}$. Ritmos biológicos ${ }^{[12]}$ são usualmente regulados por mecanismos homeostáticos para assegurar a magnitude do período ou, de modo geral, as funções relógio fisiológicas independentemente das mudanças de temperatura no ambiente. De fato, compensação de temperatura é freqüentemente citada como uma propriedade essencial presentes nos ritmos circadianos e ultradianos ${ }^{[13-16]}$. Casos onde o coeficiente de temperatura é considerado menor do que 1 são referidos como sobre-compensação e refletem uma situação contra-intuitiva na qual os processos tornam-se mais lentos quando a temperatura aumenta. Tal comportamento resultaria, vide Equação 1.1.3, em energia de ativação negativa. Ademais, quando $q_{10} \sim 1$, a energia de ativação aproxima-se para zero. Etapas reacionais elementares evidenciando valores não usuais de energia de ativação têm sido discutido por Benson e colaboradores ${ }^{[17-19]}$.

O conceito de balanço antagônico ${ }^{[20,21]}$, considerando um conjunto de energias de ativação, é dado pelo contra-balanço do ciclo de retro-alimentação positivo em relação ao ciclo de retro-alimentação negativo de tal forma que compensação de temperatura é atingida. Neste sentido, homeostase no período oscilatório resultaria do balanço antagônico para todos os parâmetros físico-químicos ou fisiológicos que influenciam o mecanismo regulatório. Como exemplo, Huang et al. ${ }^{[22]}$ mostraram que compensação de temperatura nos ritmos circadianos na Drosophila poderiam, em princípio, ser causadas pela interação proteínaproteína compostas de interações inter- e intra-moleculares com similares coeficientes de temperatura. Sob a perspectiva mecanística em bioquímica, tem sido sugerido que a atividade enzimática pode ser mantida em nível ótimo sobre considerável intervalo de temperatura e pressão hidrostática, principalmente pela diminuição da entalpia e volume da interação ligante-enzima ${ }^{[23]}$. 
Sistemas químicos afastados do equilíbrio termodinâmico têm sido freqüentemente utilizados como modelos biomiméticos na investigação da dinâmica complexa em processos biológicos $^{[24]}$. Exemplos clássicos são encontrados na eletro-oxidação de metais como modelos de propagação de pulsos nervosos ${ }^{[25]}$ e batimento cardíaco ${ }^{[26]}$. Neste contexto, parece ilustrativo estudar o efeito da temperatura em osciladores químicos na tentativa de avançar no entendimento de sistemas mais complicados, como os biológicos. Ruoff ${ }^{[20]}$ sugeriu que qualquer oscilador químico pode, em princípio, exibir compensação de temperatura. $\mathrm{O}$ oscilador químico mais estudado, a celebrada reação de Belousov-Zhabotinsky ${ }^{[27]}$, é conhecido por seguir a equação de Arrhenius numa grande extensão de parâmetros, e um coeficiente de temperatura de 2,5 , correspondente a uma energia de ativação global de $73 \mathrm{~kJ}$ mol $^{-1}$, são encontrados na literatura ${ }^{[28-30]}$. Ademais, esta energia de ativação foi determinada como sendo independente do catalisador utilizado ${ }^{[28]}$. Tomando como base o modelo Oregonator, Field e Noyes atribuíram a ausência de compensação de temperatura no sistema BZ à predominância de uma etapa elementar em que o aumento da taxa reacional resultaria em um decréscimo do período oscilatório. Energias de ativação em torno de 58, 68 e 89 kJ $\mathrm{mol}^{-1}$ têm sido reportados para a reação Briggs-Rauscher com ácido benzilmalônico ${ }^{[31]}$, ácido malônico $^{[32]}$ ou 1,4-ciclohexanodiona ${ }^{[33]}$ como substrato, respectivamente. Utilizando ciclohexadiona como substrato orgânico na reação Briggs-Rauscher em batelada, Kereszturi e Szalai ${ }^{[33]}$ reportaram uma região oscilatória na qual o período é ligeiramente independente da temperatura. Entretanto, a natureza transiente das oscilações e o intervalo de temperatura limitado $\left(20,25\right.$ e $\left.30^{\circ} \mathrm{C}\right)$ necessitaram de investigações mais precisas, preferivelmente sobre condições de fluxo.

Rábai e colaboradores observaram compensação de temperatura em osciladores de $\mathrm{pH}^{[34]}$ e discutiram o mecanismo enfatizando o fenômeno observado em termos do balanço antagônico $^{[35]}$. O efeito da temperatura na decomposição oscilatória de peróxido de 
hidrogênio em meio ácido na presença de iodeto de potássio (i.e. reação de Bray) tem sido estudado por Kovács et al. ${ }^{[36]}$ sob condições de fluxo e batelada. Coeficientes de temperatura de 0,67 à 1,80 fortemente dependentes das concentrações de vários reagentes foram encontrados num intervalo de $10^{\circ} \mathrm{C}$.

\subsection{OSCILADORES ELETROQUÍMICOS DO TIPO HN-NDR}

A maioria dos processos que ocorrem na interface sólido/líquido podem apresentar instabilidades dinâmicas em determinada faixa de parâmetros experimentais ${ }^{[5-7]}$. Cinética complexa em sistemas eletroquímicos está relacionada à presença de auto-catálise no potencial do eletrodo expressa na forma de uma resistência diferencial negativa (negative differential resistance, NDR) na curva estacionária corrente-potencial ${ }^{[37,38]}$. Neste sentido, reações eletrocatalíticas são susceptíveis a instabilidades dinâmicas graças à competição por sítios ativos entre diferentes intermediários de reação e conseqüente dependência das respectivas isotermas de adsorção em relação ao potencial ${ }^{[8]}$. Na ausência de outros ciclos de retro-alimentação, auto-catálise no potencial do eletrodo pode resultar em bi-estabilidade (i.e. presença de dois estados estáveis nos mesmos valores de parâmetros). No entanto, a adição de um ciclo de retro-alimentação negativo pode ocasionar o surgimento de oscilações periódicas. Oscilações mistas e caos surgem da criação de um grau de liberdade adicional e, portanto, um aumento da dimensão no espaço de fase ${ }^{[39]}$.

A ocorrência espontânea da dinâmica oscilatória em sistemas eletroquímicos pode ser explicada pela facilidade de atingir a NDR. A possível origem foi discutida detalhadamente por $\operatorname{Koper}^{[40]}$. Considerando a expressão geral para a corrente faradaica, 


$$
i_{F}=n F A\left(\varphi_{D L}\right) k\left(\varphi_{D L}\right) c\left(\varphi_{D L}\right)
$$

neste caso, a impedância faradaica é dada por,

$$
Z_{F}^{-1}=\frac{d i_{F}\left(\varphi_{D L}\right)}{d \varphi_{D L}}=n F\left[k c \frac{d A\left(\varphi_{D L}\right)}{d \varphi_{D L}}+A c \frac{d k\left(\varphi_{D L}\right)}{\varphi_{D L}}+A k \frac{d c\left(\varphi_{D L}\right)}{\varphi_{D L}}\right]
$$

onde $n$ é o número de $e^{-}$transferidos, $F$ constante de Faraday, $A$ área do eletrodo, $k$ constante de velocidade, $c$ concentração superficial do reagente e $\varphi_{D L}$ potencial da dupla camada. Pela Equação 1.2.2, observa-se que a impedância negativa é originada quando: $d A\left(\varphi_{D L}\right) / d \varphi_{D L}<0$, $d k\left(\varphi_{D L}\right) / d \varphi_{D L}<0$ ou $d c\left(\varphi_{D L}\right) / d \varphi_{D L}<0$. Exemplos eletroquímicos atendendo os três casos são relatados na literatura ${ }^{[4-7,41]}$.

Para modelos elétricos, a instabilidade dinâmica resulta da interação entre as características na interface eletrodo/solução (i.e. impedância faradaica) com adicionais elementos externos do circuito elétrico (i.e. capacitância do eletrodo e resistência do eletrólito) e parâmetros de controle (i.e. potencial e corrente). Assim, é de extrema importância o conhecimento do circuito equivalente da célula eletroquímica, vide Figura 1.

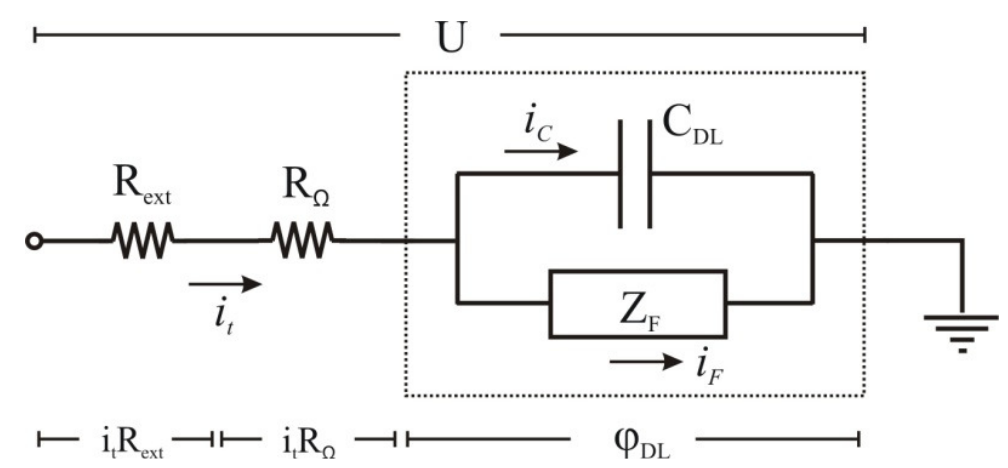

Figura 1: Circuito equivalente simplificado para a célula eletroquímica. 
Nesta representação, $U$ é o potencial aplicado, $C_{D L}$ capacitância da dupla camada, $Z_{F}$ impedância faradaica, $R_{\text {ext }}$ resistência externa inserida entre o eletrodo de trabalho e referência, $R_{\Omega}$ queda ôhmica, $i_{c}$ corrente capacitiva, $i_{F}$ corrente faradaica e $i_{t}$ corrente total. Aplicando a primeira lei de Kirchhoff (i.e. lei dos nós ou a conservação das cargas) no circuito equivalente dado na Figura 1, obtém-se que $i_{t}=i_{c}+i_{F}$

$$
\left(\frac{U-\varphi_{D L}}{R_{t}}\right)=C_{D L} \frac{d \varphi_{D L}}{d t}+i_{F}\left(\varphi_{D L}\right)
$$

em que $R_{t}$ representa a soma entre $R_{\text {ext }}$ e $R_{\Omega}$.

Na Equação 1.2.3 observa-se que $\varphi_{D L}$ comporta-se como uma variável em função do tempo. Neste sentido, torna-se necessário a análise de estabilidade do sistema, já que constitui um critério elementar em dinâmica não-linear e dá informação sobre a evolução de $\varphi_{D L}$. Sob regime de potencial aplicado fixo, o circuito elétrico no estado estacionário $d \varphi_{D L} / d t=0$ é,

$$
i_{F}\left(\varphi_{D L}^{S S}\right)=\frac{U-\varphi_{D L}^{S S}}{R_{t}}
$$

Assim a análise de estabilidade no estado estacionário $\varphi_{D L}{ }^{s s}$ pode ser obtida através de uma pequena perturbação $\delta \varphi_{D L}$,

$$
\varphi_{D L}=\varphi_{D L}^{S S}+\delta \varphi_{D L}
$$

se a perturbação for pequena, a corrente faradaica responde de modo linear de acordo com, 


$$
i_{F}\left(\varphi_{D L}\right)=i_{F}\left(\varphi_{D L}^{S S}+\delta \varphi_{D L}\right)=i_{F}\left(\varphi_{D L}^{S S}\right)+\left(\frac{d i_{F}\left(\varphi_{D L}\right)}{d \varphi_{D L}}\right)_{\varphi_{D L}=\varphi_{D L}^{S S}}
$$

Substituindo-se as Equações 1.2.5 e 1.2.6 em 1.2.4, é obtida a evolução,

$$
\frac{d \varphi_{D L}}{d t}=-C_{D L}^{-1}\left(\frac{1}{Z_{F}}+\frac{1}{R_{t}}\right) \delta \varphi_{D L}
$$

obviamente a pequena flutuação aumentara de maneira auto-catalítica se $\left(Z_{F}^{-1}+R_{t}^{-1}\right)<0$. Neste caso, a perda de estabilidade do ponto fixo apenas acontecerá se as duas condições nas Inequações 1.2.8 são preenchidas simultaneamente,

$$
Z_{F}<0 \text { e } R_{t}>\left|Z_{F}\right|
$$

Nota-se claramente a importância da impedância faradaica negativa e a resistência externa conectada em série com o eletrodo de trabalho em regime potenciostático. A interpretação física para este resultado é que oscilações de corrente necessitam de uma $R_{\text {ext }}$, funcionando como um parâmetro de bifurcação. Ademais, para o caso limite,

$$
i_{F}\left(\varphi_{D L}\right) \rightarrow \lim _{n \rightarrow \infty} \frac{U_{n}}{R_{n}}
$$

ou seja, em modo de operação galvanostático as condições estabelecidas pelas Inequações 1.2.8 são equivalentes.

Em sistemas eletroquímicos a NDR pode se manifestar na curva estacionária de corrente/potencial na forma de " $\mathrm{N}$ " ou " $\mathrm{S}$ "[38], sendo $\varphi_{D L}$ a variável auto-catalítica no primeiro caso e inibidora no último. Em termos de nomenclatura são classificados como sistemas do 
tipo N-NDR e S-NDR. A partir das similaridades mecanísticas entre as reações de eletrooxidação moléculas orgânicas pequenas, postula-se usualmente que as instabilidades dinâmicas resultantes nesses sistemas pertencem à classe dos osciladores eletroquímicos do tipo $\mathrm{HN}-\mathrm{NDR}^{[8]}$. A nomenclatura deve-se à presença de uma NDR em uma curva de polarização em forma de "N" parcialmente escondida (hidden, H) em condições voltamétricas. O termo hidden aparece devido à adsorção de espécies eletroativas em baixos potenciais que bloqueiam o processo reacional, escondendo a NDR. Simulações obtidas do modelo genérico proposto por Krischer et $a l .{ }^{[7]}$ para um oscilador do tipo HN-NDR, são observadas na Figura 2.

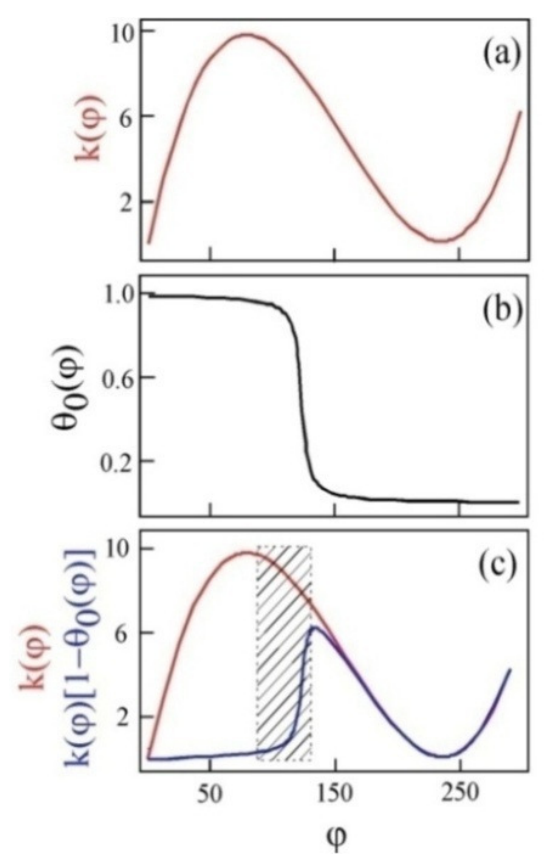

Figura 2: Simulações obtidas a partir do modelo genérico para sistemas do tipo HN-NDR proposto por Krischer et al. ${ }^{[7]}$. (a) curva estacionária em forma de "N", (b) isoterma de adsorção da espécie "bloqueante" e (c) curva estacionária (azul) resultante de (a) + (b).

Observa-se em (a) a curva estacionária em forma de "N" (vermelho), originando a NDR, (b) a isoterma de adsorção da espécie "bloqueante" (preto) e (c) a curva estacionária 
resultante (azul) da interação entre as curvas em vermelho e preto. Note que experimentalmente em condições estacionárias a região da resistência diferencial negativa aparece com uma inclinação positiva (região rachurada) no sistema do tipo HN-NDR, devido ao bloqueio superficial em baixos potenciais.

Considerando as condições necessárias para a perda de estabilidade auto-catalítica do estado estacionário por meio da NDR em regime potenciostático e galvanostático, a emergência das oscilações via oscilador eletroquímico do tipo HN-NDR apenas é alcançada com a inserção de um ciclo de retro-alimentação negativo. Este ciclo inclui uma variável inibidora no modelo genérico o que corresponde a inserir um grau de liberdade no sistema. Neste caso, com no mínimo duas variáveis, a condição de Hopf (i.e. o nascimento de um ciclo limite estável) pode ser satisfeita ${ }^{[42,43]}$. Na Figura 3 é mostrado um esquema generalizado da interação entre os ciclos de retro-alimentação positivo e negativo responsáveis pelo nascimento das oscilações durante a eletro-oxidação de moléculas orgânicas pequenas.

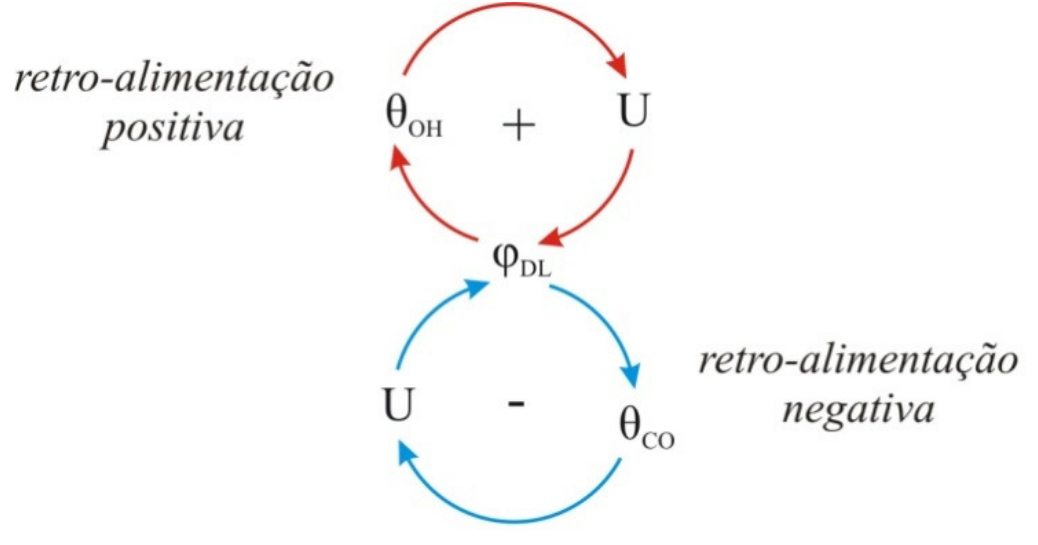

Figura 3: Esquema generalizado da interação entre os ciclos de retro-alimentação positivo e negativo responsáveis pelas oscilações observadas na reação de eletrooxidação de moléculas orgânicas pequenas ${ }^{[8]}$.

Mecanisticamente, os ciclos de retro-alimentação envolvidos na dinâmica oscilatória estão relacionados à interação entre as isotermas de adsorção dependentes do potencial das 
espécies "bloqueantes" como $\mathrm{CO}_{\mathrm{ad}}$ e $\mathrm{OH}_{\mathrm{ad}}$ que envenenam a reação de fundo. Considere inicialmente que o sistema se encontra sob controle galvanostático e que o potencial do eletrodo, $\varphi_{D L}$, sofra uma pequena flutuação para valores ligeiramente positivos. Em resposta a essa flutuação de $\varphi_{D L}$ a cobertura de $\mathrm{OH}_{\mathrm{ad}}$ aumenta de maneira auto-catalítica, acarretando o aumento do potencial aplicado, $U$ (ciclo de retro-alimentação positivo). Adotando certo atraso, a variável inibidora $\mathrm{CO}_{\mathrm{ad}}$ reage com $\mathrm{OH}_{\mathrm{ad}}$ via o mecanismo de Langmuir-Hinshelwood de forma a promover o processo de reativação superficial, disponibilizando novamente sítios ativos para a etapa auto-catalítica e diminuindo os valores de $U$ (ciclo de retro-alimentação negativo). Uma importante característica dos osciladores classificados como HN-NDR é que, mecanisticamente, eles possuem os pré-requisitos necessários para oscilarem tanto em modo galvanostático (i.e oscilações de potencial) quanto em modo potenciostático (i.e. oscilações de corrente) $)^{[38]}$.

\subsection{ELETRO-OXIDAÇÃO DE ÁCIDO FÓRMICO SOBRE PLATINA}

A eletro-oxidação de moléculas orgânicas do tipo C1 é de grande interesse sob o ponto de vista tecnológico e fundamental ${ }^{[44]}$. Apesar de progressos significantes no entendimento das rotas reacionais nestas importantes reações de oxidação, muitos aspectos mecanísticos ainda permanecem obscuros. Questões de grande importância tais como o papel da estrutura superficial na atividade, o efeito do material do eletrodo, etc. têm sido abordadas utilizando monóxido de carbono, ácido fórmico e metanol como moléculas modelo ${ }^{[45]}$. É postulado que a eletro-oxidação de moléculas orgânicas pequenas procedem através um mecanismo conhecido como dual ${ }^{[46-48]}$ no qual duas vias paralelas acontecem simultaneamente. A via direta ocorre pela formação de um intermediário ativo com pequeno tempo de vida que uma vez formado, é 
rapidamente convertido ao produto final, $\mathrm{CO}_{2}$. $\mathrm{Na}$ via indireta monóxido de carbono adsorvido "envenena" a superfície do eletrodo, sendo oxidado à $\mathrm{CO}_{2}$ pela reação com espécies oxigenadas, $\left(\mathrm{H}_{\mathrm{x}}\right) \mathrm{O}_{\text {ad }}$ pelo mecanismo de Langmuir-Hinshelwood. Neste caso, $x$ pode ser $0,1,2$ de acordo com a natureza da espécie oxigenada adsorvida.

Devido às recentes observações espectroscópicas indicando a presença de formato (i.e. $\mathrm{HCOO}_{\mathrm{ad}}$ ) adsorvido durante a eletro-oxidação de ácido fórmico (EAF), o mecanismo paralelo dual tem sido recentemente revisado. Osawa e colaboradores ${ }^{[49]}$ empregaram a técnica espectroscopia de absorção de infravermelho superficialmente intensificada (surface enhanced infrared absorption spectroscopy, SEIRAS) em modo de reflexão total atenuada (attenuated total reflection, ATR) do tipo Kretschmann no estudo de oscilações de potencial durante a EAF sobre platina policristalina em meio ácido. Os autores encontraram que os recobrimentos de $\mathrm{CO}_{\mathrm{L}}$ e $\mathrm{HCOO}_{\mathrm{ad}}$ oscilam de modo sincronizado com potencial entre $(0,2) 0,1$ $<\theta_{C O L}<(0,3) 0,25$ e $(0,1) 0,05<\theta_{H C O O}<(0,2) 0,15$ monocamadas em $(3,2 \mathrm{~mA}) 10 \mathrm{~mA}$, respectivamente. Ademais, sugerem que formato (adsorvido via configuração de ponte pelos oxigênios) é o intermediário ativo na via direta para a EAF sobre platina policristalina e sua decomposição oxidativa para $\mathrm{CO}_{2}$ como a etapa determinante da reação ${ }^{[50-52]}$, concluindo que a taxa de oxidação de ácido fórmico é governada por uma função não-linear dos recobrimentos de formato e monóxido de carbono adsorvidos na superfície metálica. Behm e colaboradores $^{[53]}$ mostraram que a contribuição da via indireta na corrente faradaica total é menor que $1 \%$ em $\mathrm{U} \leq 0,60 \mathrm{~V}$ à $25^{\circ} \mathrm{C}$ e $5 \%$ em $\mathrm{U} \leq 0,70 \mathrm{~V}$ à $80^{\circ} \mathrm{C}$, demonstrando que a via direta é possivelmente a via dominante durante a EAF. No entanto, não atribuíram o formato como o intermediário ativo na via direta. Neste caso, a hipótese sugerida é que formato estaria atuando como um espectador, bloqueando a catálise superficial na via dominante ${ }^{[54]}$ o que corresponde um mecanismo proveniente de três rotas reacionais. Formato como intermediário ativo também foi encontrado durante a eletro-oxidação de metanol ${ }^{[55]}$ e formaldeído ${ }^{[56]}$ sobre 
platina policristalina. Neste caso, a análise do processo reacional torna-se mais complicado devido à formação de diversos intermediários de reação que participam das etapas de oxidação à $\mathrm{CO}_{2}$.

Com a finalidade de fundamentar a discussão nos resultados experimentais através das vias reacionais, é adotado neste trabalho o mecanismo de oxidação de ácido fórmico proposto por Osawa e colaboradores ${ }^{[49]}$. A Figura 4 representa de maneira esquemática as etapas elementares da EAF sobre platina policristalina.

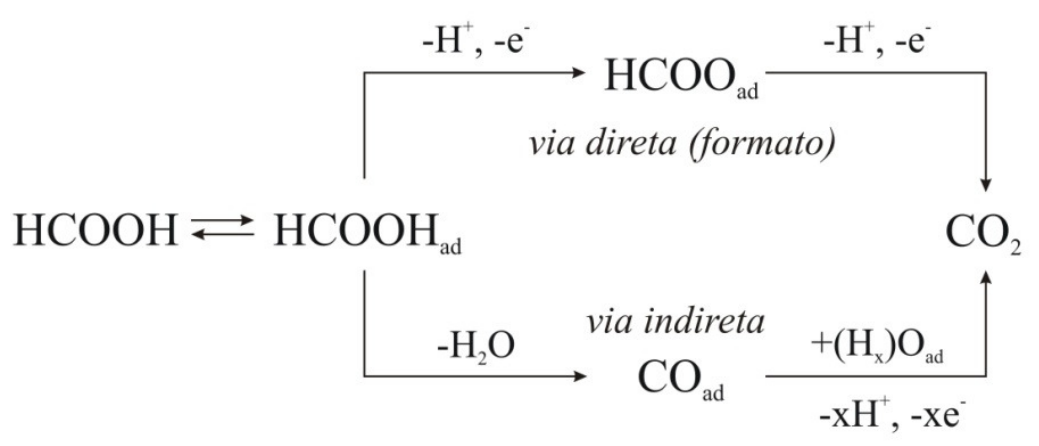

Figura 4: Mecanismo geral da eletro-oxidação de ácido fórmico (EAF) sobre platina policristalina.

O processo de oxidação inicia-se com a adsorção da molécula de ácido fórmico na superfície metálica, neste momento duas rotas reacionais, direta e indireta, podem ocorrer simultaneamente: A via direta, referente à formação de formato como intermediário ativo e sua decomposição oxidativa para $\mathrm{CO}_{2}$ acontece por meio de uma rotação frustrada ${ }^{[51]}$ (i.e. a quebra da ligação C-H ocorre quando a molécula de formato é altamente inclinada a um sítio superficial livre adjacente à sua posição de adsorção). Evidências experimentais em ultra alto vácuo (ultra high vacuum, UHV) corroboram a idéia proposta: a decomposição de formato para $\mathrm{CO}_{2}$ é notavelmente suprimida pela alta co-adsorção de outras espécies ou pelo próprio recobrimento excessivo de formato ${ }^{[57]}$. A explicação para este fenômeno seria a ocupação dos 
sítios superficiais livres adjacentes, diminuindo o recobrimento livre total o que prejudicaria o processo da rotação frustrada. Neste caso, a cinética de decomposição é dada por uma equação não-linear de segunda ordem, quesito necessário para o aparecimento da NDR. A via indireta, resulta na formação de $\mathrm{CO}_{\mathrm{ad}}$ adsorvido na forma linear e ponte, sendo oxidados em altos potenciais à $\mathrm{CO}_{2}$ pela reação com espécies oxigenadas, $\left(\mathrm{H}_{\mathrm{x}}\right) \mathrm{O}_{\mathrm{ad}}$ via o mecanismo de Langmuir-Hinshelwood. O processo de oxidação inicia-se acima de $0,60 \mathrm{~V}$, extinguindo por completo o recobrimento de monóxido de carbono em 1,00 V, aproximadamente. Acima deste potencial a formação de espécies oxigenadas é favorecida inibindo a decomposição e estabilizando a molécula de formato o que torna possível sua presença na superfície até 1,30 V. O processo de formação e $\mathrm{CO}_{\mathrm{L}}$ é lento em relação à formação de $\mathrm{CO}_{\mathrm{B}}$ e $\mathrm{HCOO}_{\mathrm{ad}} \mathrm{e}$ altamente dependente de outras espécies previamente adsorvidas devido à competição por sítios ativos livres. Neste sentido, a Samjeské et al ${ }^{[49]}$ sugeriram a seguinte seqüência de força de adsorção: $\mathrm{CO}_{\mathrm{ad}}>\mathrm{HCOO}_{\mathrm{ad}}>(\mathrm{H}) \mathrm{SO}_{4}{ }^{-}>\left(\mathrm{H}_{\mathrm{x}}\right) \mathrm{O}_{\mathrm{ad}}$. Sob condições oscilatórias, o recobrimento de $\theta_{C O B}$ permaneceu independente do tempo e da densidade de corrente aplicada, resultando em $\theta_{C O B} \sim 0,1$ o que torna o recobrimento de monóxido de carbono linearmente adsorvido a única espécie resultante da via indireta que acompanha as oscilações de potencial. 


\section{OBJETIVOS}

A investigação sistemática da influência da temperatura na dinâmica oscilatória durante a eletro-oxidação de ácido fórmico sobre platina é objetivo central desta dissertação. A caracterização do efeito da temperatura é dada pelo cálculo da energia de ativação aparente em condições voltamétricas e valores de $q_{10}$ sob regime oscilatório. As séries temporais foram estudadas em modo galvanostático em cinco temperaturas diferentes no intervalo de 5 à 25 ${ }^{\circ} \mathrm{C}$. Os resultados são discutidos em termos de uma intricada combinação entre temperatura e a distância do equilíbrio na determinação do período e amplitude das oscilações. Adicionalmente, a partir da modelagem dos resultados experimentais, foram realizadas algumas simulações numéricas. As discussões foram realizadas com base em considerações mecanísticas em conexão com o entendimento no estado-da-arte dos aspectos eletrocatalíticos na oxidação de ácido fórmico sobre platina. 


\section{EXPERIMENTAL}

Utilizou-se uma célula eletroquímica convencional caracterizada por três eletrodos. Eletrodo de trabalho (WE) constitui de uma placa de platina policristalina lisa com $0,2 \mathrm{~cm}^{2}$ de área geométrica e rugosidade de 3,15 (valor calculado assumindo $210 \mu \mathrm{C} \mathrm{cm}^{-2}$ para a oxidação de uma monocamada de hidrogênio, sob condições voltamétricas). Uma rede de platina platinizada de área muito superior ao do WE foi utilizada como contra-eletrodo (CE). O eletrodo reversível de hidrogênio (RHE) preparado com concentração idêntica àquela de ácido sulfúrico do eletrólito de suporte foi utilizado como eletrodo de referência (RE) e colocado em um compartimento separado do corpo principal da célula eletroquímica mantido à $25^{\circ} \mathrm{C}$. As soluções foram preparadas com água de alta pureza (sistema Milli-Q 18,2 M $\Omega \mathrm{cm}$, Millipore) a partir de ácidos, sulfúrico (Merck, 98\%) e fórmico (Fluka, 98\%). Antes de cada experimento o WE foi ciclado à $\mathrm{dU} / \mathrm{dt}=0,10 \mathrm{~V} \mathrm{~s}^{-1}$ entre 0 e $1,30 \mathrm{~V}$ por cerca de uma hora, garantindo uma estrutura superficial reproduzível e o eletrólito de suporte foi deaerado com borbulhamento de nitrogênio por no mínimo 15 minutos e depois mantido sob atmosfera inerte. Finalmente, as medidas eletroquímicas foram realizadas com um potenciostato/galvanostato Autolab/Eco-Chemie PGSTST30 e a temperatura da célula foi mantida constante pelo termostato da Marconi modelo MA-184.

O prosseguimento dos experimentos eletroquímicos deram início após a identificação do perfil voltamétrico da platina policristalina em meio ácido, usualmente reportado na literatura corrente ${ }^{[58]}$. A “impressão digital” do perfil voltamétrico é mostrada na Figura 5. 


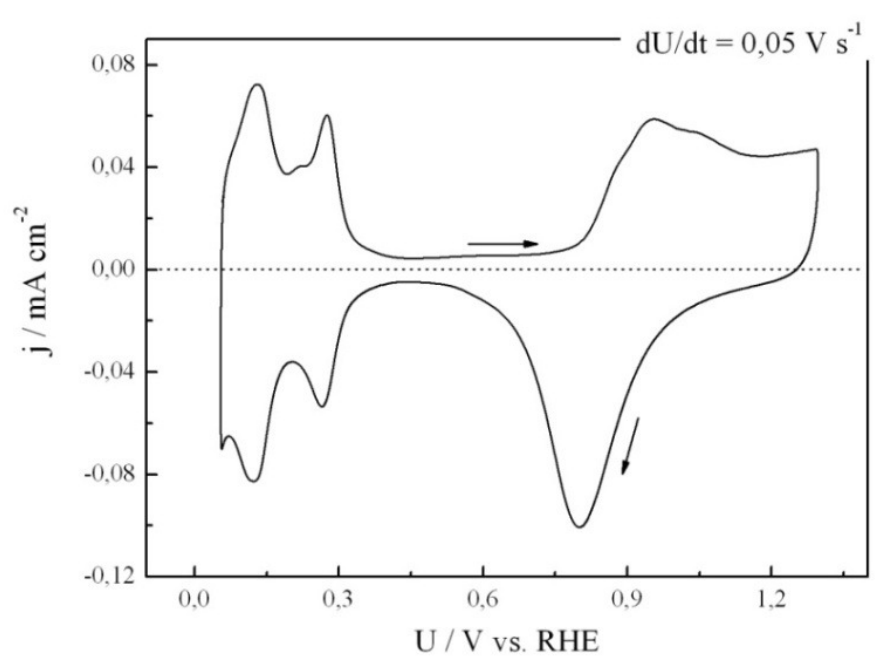

Figura 5: Voltametria cíclica de platina policristalina em ácido sulfúrico obtido à $\mathrm{dU} / \mathrm{dt}=0,05 \mathrm{~V} \mathrm{~s}^{-1} \cdot\left[\mathrm{H}_{2} \mathrm{SO}_{4}\right]=0,1 \mathrm{~mol} \mathrm{~L}^{-1} \mathrm{e} \mathrm{T}=25^{\circ} \mathrm{C}$.

As curvas potenciodinâmicas foram realizadas com velocidade de varredura de dU/dt $=0,05 \mathrm{~V} \mathrm{~s}^{-1}$ no intervalo de 0,05 à $1,30 \mathrm{~V}$. Observa-se com clareza a definição dos picos reversíveis de corrente entre 0,05 à $0,30 \mathrm{~V}$ referentes à região de oxidação/redução de hidrogênio em ácido sulfúrico e histerese em altos potenciais ocasionada pela formação de óxidos de platina em aproximadamente, 0,80 V. A ausência de picos estranhos e a simetria da dupla camada em relação ao zero de densidade de corrente, retrata além da limpeza do sistema o deareamento do meio reacional por nitrogênio, respectivamente. Quesitos obrigatórios para o início dos experimentos. 


\section{Modelagem e SimulaçõeS}

Graças à importância da dinâmica oscilatória no processo de auto-organização espaçotemporal na interface sólido/líquido, investigações experimentais e teóricas por meio de integração numérica foram propostas na tentativa de elucidar o mecanismo genérico para um oscilador eletroquímico ${ }^{[4-7]}$. Neste sentido, a modelagem matemática via construção das equações diferenciais ordinárias (EDO) das etapas elementares apresenta-se como uma ferramenta muito importante na interpretação dos resultados, devido à fácil acessibilidade aos parâmetros do sistema, o que usualmente não acontece no âmbito experimental.

Oscilações de potencial e corrente durante a EAF tem sido simuladas matematicamente considerando o mecanismo dual ${ }^{[46-48]}$. Os modelos propostos geralmente assumem a espécie $\underline{\mathrm{COOH}}_{\mathrm{ad}}$ (adsorvido pelo carbono) como intermediário ativo e sua formação como a etapa determinante da reação. Evidências experimentais suportando esta hipótese não foram encontradas, o que ocasionou no processo de modelagem a eliminação adiabática do intermediário ativo na via direta, considerando sua rápida conversão a $\mathrm{CO}_{2}$. Exemplos clássicos são encontrados nos trabalhos de Albahadily et al ${ }^{[59]}$ onde séries temporais de potencial foram simuladas por meio de nove e dez EDO's e pelo menos seis intermediários superficiais foram considerados. Strasser et al. ${ }^{[60]}$ observaram uma dinâmica temporal de caráter mais complexo como oscilações mistas e caos, admitindo não apenas as reações superficiais, mas um atraso difusional do reagente à superfície metálica. Considerando um modelo simples de três EDO's Okamoto et al.$^{[61]}$ sugeriram que existe um número mínimo de etapas reacionais suficientes para a descrição das oscilações, mesmo num conjunto de reações simultâneas como a EAF.

No entanto, recentemente Osawa e colaboradores ${ }^{[49]}$ através da técnica ATR-SEIRAS identificaram $\mathrm{HCOO}_{\mathrm{ad}}$ como intermediário ativo da EAF sobre platina policristalina. Foi 
observado que o recobrimento de formato oscila de forma sincronizada com o potencial e que sua oxidação para $\mathrm{CO}_{2}$ é a etapa determinante da reação. Estes novos resultados experimentais ocasionaram uma revisão dos modelos já existentes e um novo modelo foi sugerido para a EAF considerando formato como intermediário ativo. De fato, o modelo proposto por Mukouyama et al. ${ }^{[52]}$ representa além do comportamento oscilatório a NDR em condições voltamétricas, capturando de modo aceitável a magnitude das variáveis como recobrimento das diversas espécies e potencial da dupla camada. Entretanto, Mukouyama et $a l .^{[52]}$ não consideraram a etapa de desidrogenação da água na formação de óxidos de platina (i.e. $\left(\mathrm{H}_{\mathrm{x}}\right) \mathrm{O}_{\mathrm{ad}}, x=0$ e 1$)$ em altos potenciais, assumiram apenas que $\mathrm{CO}_{\mathrm{L}}$ é oxidado a partir de moléculas de $\mathrm{H}_{2} \mathrm{O}_{\text {ad }}$ previamente adsorvidas na superfície do eletrodo. Como já conhecido na literatura, a formação de espécies oxigenadas possui papel fundamental no processo de reativação superficial ${ }^{[62]} \mathrm{e}$, portanto, passível de inclusão nos ciclos de retro-alimentação presentes durante a EAF em regime oscilatório. Outro aspecto importante a ser ressaltado é que oscilações de potencial usualmente atingem valores superiores à $0,80 \mathrm{~V}$ (i.e. referente ao início da oxidação superficial) experimentalmente, levando-se em conta a queda ôhmica.

Propõe-se aqui um novo modelo. São consideradas apenas as etapas essenciais para a descrição da eletro-oxidação de ácido fórmico de forma a completar as lacunas presentes nos modelos já existentes. O conjunto de reações químicas $(r i, i=0,1, \ldots, 5)$ é dado abaixo,

$$
\begin{aligned}
& \mathrm{HCOOH}+2 * \rightleftharpoons \mathrm{HCOO}_{a d}+\mathrm{H}^{+}+e^{-} \\
& \mathrm{HCOO}_{a d}+* \rightarrow \mathrm{CO}_{2}+3 *+\mathrm{H}^{+}+e^{-} \\
& \mathrm{HCOOH}+* \rightarrow \mathrm{CO}_{L}+\mathrm{H}_{2} \mathrm{O} \\
& \mathrm{H}_{2} \mathrm{O}+* \rightleftharpoons \mathrm{OH}_{a d}+H^{+}+e^{-} \\
& \mathrm{CO}_{L}+\mathrm{OH}_{a d} \rightarrow \mathrm{CO}_{2}+2 *+H^{+}+e^{-}
\end{aligned}
$$


A reação (r1) indica o processo de adsorção do ácido fórmico na superfície metálica, necessitando no mínimo de dois sítios superficiais livres, denotados pelo asterisco, para a formação do intermediário ativo $\mathrm{HCOO}_{\mathrm{ad}}$ adsorvido na configuração molecular de ponte. A reação (r2) mostra a taxa de conversão de formato adsorvido para dióxido de carbono. Nota-se que $\mathrm{HCOO}_{a d}$ necessita de um sítio superficial livre para o processo de decomposição oxidativa, gerando uma lei de velocidade de segunda ordem. Este quesito é fundamental para o aparecimento da $\mathrm{NDR}^{[49]}$ e obedece à observações experimentais em $\mathrm{UHV}^{[57]}$ em que o processo de decomposição acontece por meio de uma rotação frustrada da molécula de formato, necessitando de um sítio livre adjacente para a oxidação à $\mathrm{CO}_{2}$. A reação (r3) representa o processo de formação de monóxido de carbono pela dissociação da molécula de ácido fórmico. Neste caso, em particular, é considerado apenas a formação de $\mathrm{CO}_{\mathrm{L}}\left(\mathrm{CO}_{\mathrm{ad}}\right.$, linear) enquanto que $\mathrm{CO}_{\mathrm{B}}\left(\mathrm{CO}_{\mathrm{ad}}\right.$, bridge ou ponte) permanece praticamente constante durante as oscilações. Experimentos de ATR-SEIRAS ${ }^{[49]}$ indicam que o recobrimento de $\mathrm{CO}_{\mathrm{B}}$ permanece em torno de $\theta_{C O B} \sim 0,1$ e que a taxa de conversão de $\mathrm{CO}_{\mathrm{L}}$ para $\mathrm{CO}_{\mathrm{B}}$ é negligível. Observa-se também que o processo de desidratação na geração de $\mathrm{CO}_{\mathrm{ad}}$ neste modelo proposto, requer apenas um sítio livre disponível. A reação (r4) representa o processo de dissociação da água em altos potenciais formando espécies oxigenadas como $\mathrm{OH}_{\mathrm{ad}}$, estas são oxidadas à $\mathrm{CO}_{2}$ na reação com $\mathrm{CO}_{\mathrm{L}}$ através o mecanismo de Langmuir-Hinshelwood, vide reação ( $\mathrm{r} 5)$. A formação de $\mathrm{H}_{2} \mathrm{O}_{\mathrm{ad}}$ e $\mathrm{O}_{\mathrm{ad}}$, respectivas espécies para $x=0$ e 2 , foram desconsideradas.

Assim, com intuito de elaborar as EDO's referentes aos processos mencionados pelas reações químicas ( $r i, i=0,1, \ldots, 5)$ algumas suposições foram assumidas: (a) as reações redox obedecem a equação cinética de Butler-Volmer ${ }^{[63]}$, 


$$
j=j^{0}\left\{\exp \left[\frac{\alpha_{i} n F \varphi_{D L}}{R T}\right]-\exp \left[\frac{-\left(1-\alpha_{i}\right) n F \varphi_{D L}}{R T}\right]\right\}
$$

separando-se algebricamente as contribuições anódica e catódica da Equação 4.1, tem-se,

$$
k_{i}^{\prime}=k_{i} \exp \left[\frac{\alpha_{i} n F \varphi_{D L}}{R T}\right] \quad e \quad k_{-i}^{\prime}=k_{-i} \exp \left[\frac{-\left(1-\alpha_{i}\right) n F \varphi_{D L}}{R T}\right]
$$

onde $k_{i}^{\prime}$ e $k_{-i}^{\prime}$ são as constante de velocidade da etapa eletroquímica anódica e catódica da reação $i$, respectivamente. O mesmo se aplica para as constantes de velocidade $k_{i}$ e $k_{-i}$ da etapa química, $\alpha_{i}$ é o coeficiente de transferência, $n$ número de $e^{-}$transferidos, $F$ constante de Faraday, $R$ constante dos gases, $T$ temperatura e $\varphi_{D L}$ potencial da dupla camada elétrica; (b) a dupla camada elétrica comporta-se como um capacitor ideal de placas paralelas; (c) desprezase o efeito de transporte de massa difusional na camada de Nernst do ácido fórmico à superfície metálica, assumindo a presença uniforme do reagente em toda a região do eletrodo; (d) desprezam-se as interações entre adsorbato/adsorbato (i.e. parâmetros de Frumkin) no processo de adsorção/dessorção; (e) despreza-se o processo de place exchange (i.e. Pt-O $\rightarrow$ $(\mathrm{O}-)_{\text {sub }} \mathrm{Pt}$ ) durante a formação de óxidos de platina em altos potenciais, adotando apenas $\mathrm{OH}_{\mathrm{ad}}$ como espécie oxigenada; (f) considera-se as concentrações molares de $\mathrm{HCOOH} \mathrm{e} \mathrm{H}_{2} \mathrm{O}$ em solução como unitárias (i.e. 1,0 mol $\mathrm{L}^{-1}$ ); (g) despreza-se o efeito da temperatura nas constantes de velocidade das etapas químicas $k_{i}$ e por fim, (h) assume-se o formato adsorvido como intermediário ativo na via direta. De posse das seguintes condições de contorno, é possível representar o modelo de reações químicas através de um sistema de quatro EDO's correspondentes à conservação de massa e carga, 


$$
\begin{aligned}
& \frac{d \theta_{H C O O}}{d t}=k_{1}^{\prime} \theta_{V}^{2}-k_{-1}^{\prime} \theta_{H C O O}-k_{2}^{\prime} \theta_{H C O O} \theta_{V} \\
& \frac{d \theta_{C O_{L}}}{d t}=k_{3} \theta_{V}-k_{5}^{\prime} \theta_{C O_{L}} \theta_{O H} \\
& \frac{d \theta_{O H}}{d t}=k_{4}^{\prime} \theta_{V}-k_{-4}^{\prime} \theta_{O H}-k_{5}^{\prime} \theta_{C O_{L}} \theta_{O H} \\
& C_{D L} \frac{d \varphi_{D L}}{d t}=j_{t}-n F S\left[\left(v_{1}-v_{-1}\right)+v_{2}+\left(v_{4}-v_{-4}\right)+v_{5}\right]
\end{aligned}
$$

Neste conjunto de equações, $j_{t}$ representa a densidade de corrente total aplicada, $C_{D L}$ a capacitância e $\varphi_{D L}$ o potencial da dupla camada, $v_{i}$ velocidade da reação $i, S$ a área real do eletrodo, $\theta_{\mathrm{HCOO}}$ é referente ao recobrimento de formato, $\theta_{\mathrm{COL}}$ recobrimento de $\mathrm{CO}_{\mathrm{ad}}$ linear, $\theta_{O H}$ recobrimento da espécie oxigenada $\mathrm{OH}_{\mathrm{ad}}$ e $\theta_{V}$ a quantidade de sítios ativos vacantes ou disponíveis, sendo

$$
\theta_{V}=1-\theta_{C O_{L}}-2 \theta_{C O_{B}}-2 \theta_{H C O O}-\theta_{O H}
$$

O índice " 2 " representa a geometria molecular de adsorção em forma de ponte. Note que o recobrimento de $\mathrm{CO}_{\mathrm{B}}$ não possui sua respectiva equação de evolução devido sua invariância no tempo e corrente aplicada ${ }^{[49]}$. Neste caso, $\theta_{C O B}$ atua apenas como uma espécie bloqueante na oxidação global. As correntes de oxidação e redução possuem sinal positivo e negativo, respectivamente. A expressão geral da corrente faradaica $j_{F}$ é dada por,

$$
j_{F}=n F S \sum_{i=1}^{5}\left(v_{i}-v_{-i}\right)
$$


O sistema referente as quatro EDO's foi integrado numericamente através da ferramenta NDSolve (i.e. pacote de integração numérica equivalente ao método de RungeKutta com passo ajustável), utilizando o software disponível comercialmente Mathematica versão 6. Os valores dos parâmetros utilizados para a integração numérica são dados na Tabela I.

Tabela I: Lista de parâmetros do modelo proposto*.

\begin{tabular}{|c|c|c|c|}
\hline parâmetro & significado & valor & unidade \\
\hline $\mathrm{k}_{1}$ & constante de velocidade & $1,0.10^{3}-3,0.10^{3}$ & $\mathrm{~L} \mathrm{~mol}^{-1} \mathrm{~s}^{-1}$ \\
\hline $\mathrm{k}_{-1}$ & $/ /$ & $1,0.10^{-5}$ & $\mathrm{~s}^{-1}$ \\
\hline $\mathrm{k}_{2}$ & $/ /$ & $1,1.10^{2}-5,0.10^{2}$ & $\mathrm{~s}^{-1}$ \\
\hline $\mathrm{k}_{3}$ & $/ /$ & $0,8 \cdot 10^{2}-1,0.10^{2}$ & $\mathrm{~L} \mathrm{~mol}^{-1} \mathrm{~s}^{-1}$ \\
\hline $\mathrm{k}_{4}$ & $/ /$ & $0,6.10^{-2}-3,0.10^{-2}$ & $\mathrm{~L} \mathrm{~mol}^{-1} \mathrm{~s}^{-1}$ \\
\hline $\mathrm{k}_{-4}$ & $/ /$ & $2,0.10^{5}-3,0.10^{5}$ & $\mathrm{~s}^{-1}$ \\
\hline $\mathrm{k}_{5}$ & $/ /$ & $5,0.10^{-5}$ & $\mathrm{~s}^{-1}$ \\
\hline$\alpha_{1}$ & coeficiente de transferência & 0,5 & - \\
\hline$\alpha_{2}$ & $/ /$ & 0,3 & - \\
\hline$\alpha_{4}$ & $/ /$ & 0,6 & - \\
\hline$\alpha_{5}$ & $/ /$ & 0,5 & - \\
\hline $\mathrm{F}$ & constante de Faraday & 96500 & $\mathrm{C} \mathrm{mol}^{-1}$ \\
\hline $\mathrm{R}$ & constante dos gases & 8,314 & $\mathrm{~J} \mathrm{~K}^{-1} \mathrm{~mol}^{-1}$ \\
\hline $\mathrm{T}$ & temperatura & $278-328$ & $\mathrm{~K}$ \\
\hline $\mathrm{n}$ & número de $e^{-}$transferidos & 1 & mol \\
\hline $\mathrm{C}_{\mathrm{DL}}$ & capacitância da dupla camada & $8,0.10^{-5}$ & $\mathrm{C} \mathrm{V}^{-1} \mathrm{~cm}^{-2}$ \\
\hline S & área real & $2,2.10^{-9}$ & $\mathrm{~mol} \mathrm{~cm} \mathrm{~cm}^{-2}$ \\
\hline A & área geométrica & 0,2 & $\mathrm{~cm}^{2}$ \\
\hline $\mathrm{R}_{\Omega}$ & queda ôhmica & 5 & $\Omega$ \\
\hline$\theta_{\mathrm{COB}}$ & recobrimento de $\mathrm{CO}$ bridge & 0,1 & - \\
\hline $\mathrm{j}_{\mathrm{t}}$ & densidade de corrente total & $0,05-1,00$ & $\mathrm{~mA} \mathrm{~cm}{ }^{-2}$ \\
\hline
\end{tabular}

* valores de $k_{i}$ para $i=3,4,-4$ e 5 foram retiradas do artigo ${ }^{[60]}$ e ajustadas para o modelo. Neste caso, $\varphi_{D L}$ foi normalizado em relação à RHE pela adição de 0,24. 
Com a finalidade de checar a qualidade do modelo e dos valores dos parâmetros atribuídos em termos de comparação com os resultados experimentais, simulações da varredura potenciodinâmica positiva e as séries temporais em regime galvanostático foram conduzidas. Os primeiros resultados podem ser observados na Figura 6.

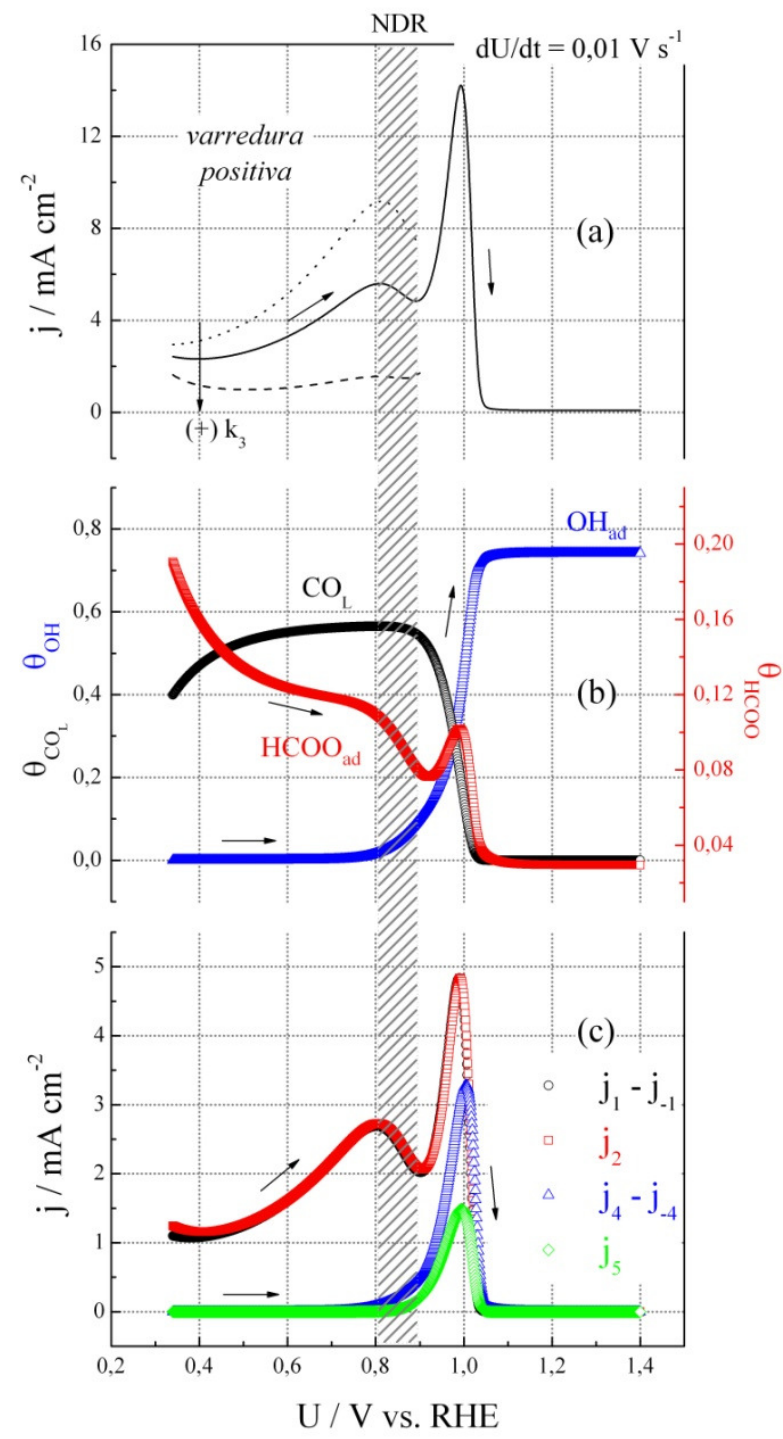

Figura 6: Simulações obtidas a partir do modelo proposto durante a EAF sobre platina para $\mathrm{dU} / \mathrm{dt}=0,01 \mathrm{~V} \mathrm{~s}^{-1} \mathrm{e} \mathrm{T}=25^{\circ} \mathrm{C}$. (a) varredura potenciodinâmica positiva, (b) isotermas de adsorção de $\mathrm{CO}_{\mathrm{L}}$ (preto), $\mathrm{HCOO}_{\mathrm{ad}}$ (vermelho) e $\mathrm{OH}_{\mathrm{ad}}$ (azul) e (c) contribuição de $\mathrm{j}_{\mathrm{i}}$ em $\mathrm{j}_{\mathrm{t}}$. A região da NDR apresenta-se como uma faixa rachurada. Parâmetros: $\mathrm{k}_{1}=2,0.10^{3} \mathrm{~L} \mathrm{~mol}^{-1} \mathrm{~s}^{-1}, \mathrm{k}_{2}=5,0.10^{2} \mathrm{~s}^{-1}, \mathrm{k}_{3}=0,8.10^{2}$ $\mathrm{L} \mathrm{mol}^{-1} \mathrm{~s}^{-1}, \mathrm{k}_{4}=0,6.10^{-2} \mathrm{~L} \mathrm{~mol}^{-1} \mathrm{~s}^{-1}, \mathrm{k}_{-4}=2,0.10^{5} \mathrm{~s}^{-1}$. 
Observa-se que o perfil potenciodinâmico e a magnitude da densidade de corrente simulada são idênticos ao encontrado experimentalmente, exceto pela posição da NDR em torno de 0,80 à $0,90 \mathrm{~V}$. Note que a supressão da NDR, curva pontilhada, ocorre pelo processo de adsorção de monóxido de carbono, sendo facilitada via o aumento da constante de velocidade da reação (r3). Situação onde se apresenta a HN-NDR é visualizada na curva potenciodinâmica tracejada. Aproveitando-se da facilidade de acesso às etapas elementares, isotermas de adsorção das espécies $\mathrm{CO}_{\mathrm{L}}$ (preto), $\mathrm{HCOO}_{\mathrm{ad}}$ (vermelho) e $\mathrm{OH}_{\mathrm{ad}}$ (azul) foram simuladas, vide Figura $6 \mathrm{~b}$. A isoterma de $\mathrm{CO}_{\mathrm{L}}$ possui perfil muito similar ao observado pela intensidade de banda em ATR-SEIRAS por Osawa e colaboradores ${ }^{[49]}$. Existe um pequeno aumento do recobrimento em baixos potenciais seguido de uma estabilização em torno de $\theta_{C O L} \sim 0,57$ e por fim o inicio da oxidação pela via indireta acima de $0,80 \mathrm{~V}$, onde a formação de óxidos de platina tal como $\mathrm{OH}_{\mathrm{ad}}$ é facilitada. Ademais, o recobrimento de $\mathrm{OH}_{\mathrm{ad}}$ satura-se em $\theta_{O H} \sim 0,75$ acima de $1,00 \mathrm{~V}$. A isoterma correspondente ao formato adsorvido não apresenta-se com perfil similar ao observado experimentalmente através da intensidade de banda em ATR-SEIRAS, porém é notório sua relação direta com a corrente faradaica total, onde a maior contribuição é dada pela via direta da EAF, vide Figura 6c. O pré-pico observado em $0,80 \mathrm{~V}$ é ocasionado pela formação e decomposição de formato, enquanto que no pico de corrente em aproximadamente $1,00 \mathrm{~V}$ corresponde a soma das cinco etapas reacionais $(r i, i=0,1, \ldots, 5)$. Após o aumento de $\theta_{O H}$ em $1,00 \mathrm{~V}$, vestígios de formato permanecem na superfície metálica, $\theta_{\mathrm{HCOO}}=0,03$ até o final da varredura positiva, $1,40 \mathrm{~V}$. Neste modelo em particular, a origem da NDR é ocasionada pela adsorção de espécies oxigenadas refletindo a diminuição do recobrimento de formato e, portanto, a diminuição da corrente faradaica. Assim de posse do conhecimento da região de potencial onde se encontra a resistência diferencial negativa, séries temporais de potencial em regime galvanostático foram simuladas, como mostra a Figura 7. 


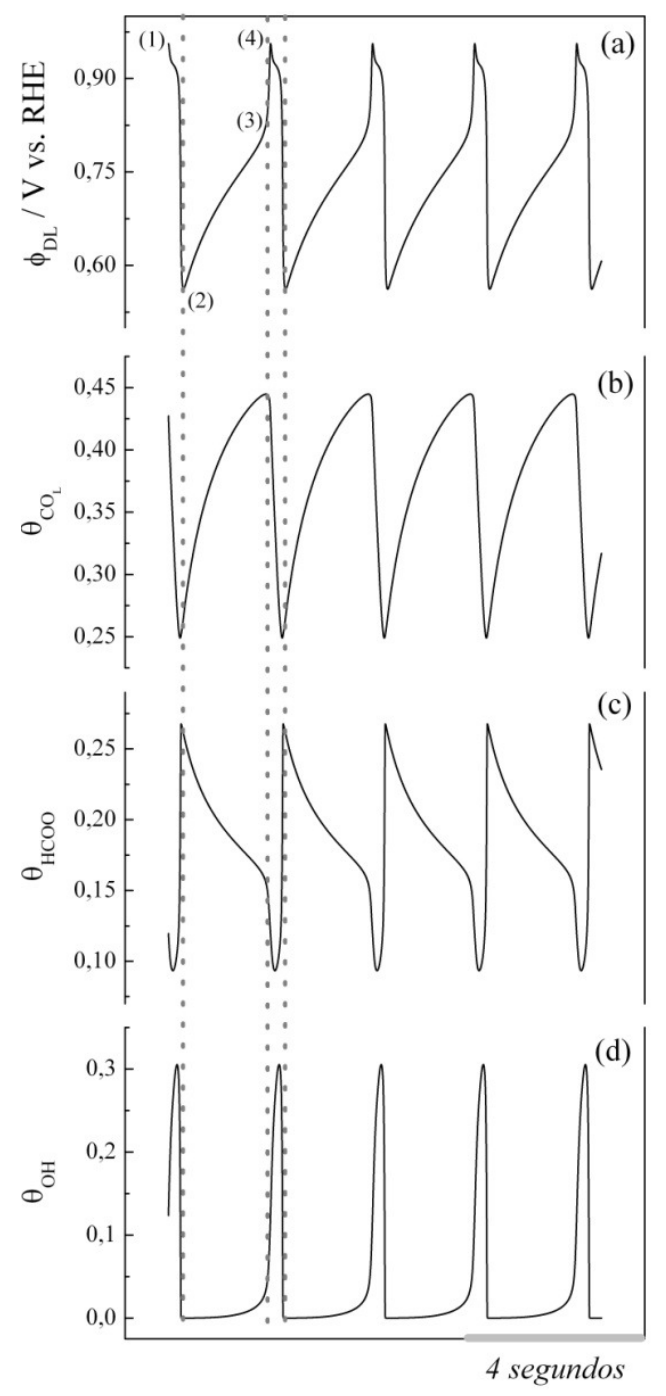

Figura 7: Simulações obtidas a partir do modelo proposto durante a EAF sobre platina para $\mathrm{j}_{\mathrm{t}}=1,0 \mathrm{~mA} \mathrm{~cm}{ }^{-2} \mathrm{e} \mathrm{T}=25^{\circ} \mathrm{C}$. Séries temporais de (a) $\varphi_{\mathrm{DL}}$, (b) $\theta_{\mathrm{COL}}$, (c) $\theta_{\mathrm{HCOO}}$ e (d) $\theta_{\mathrm{OH}}$. Parâmetros: $\mathrm{k}_{1}=3,0.10^{3} \mathrm{~L} \mathrm{~mol}^{-1} \mathrm{~s}^{-1}, \mathrm{k}_{2}=4,0.10^{2} \mathrm{~s}^{-1}, \mathrm{k}_{3}=1,0.10^{2}$ $\mathrm{L} \mathrm{mol}^{-1} \mathrm{~s}^{-1}, \mathrm{k}_{4}=3,0.10^{-2} \mathrm{~L} \mathrm{~mol}^{-1} \mathrm{~s}^{-1}, \mathrm{k}_{-4}=3,0.10^{5} \mathrm{~s}^{-1}$.

É legítimo discutir a morfologia e os valores do potencial $\varphi_{D L}$ e dos recobrimentos de $\theta_{C O L}$ e $\theta_{H C O O}$ encontrados durante as simulações que se apresentam muito próximos aos valores obtidos experimentalmente ${ }^{[49]}$. Novamente, a única exceção foi encontrada para a morfologia das oscilações de formato. Observa-se que o recobrimento de formato comportase como uma função inversa ao recobrimento de $\mathrm{CO}_{\mathrm{L}}$, esta afirmação é plausível, já que monóxido de carbono previne a decomposição oxidativa de $\mathrm{HCOO}_{\mathrm{ad}}$ à $\mathrm{CO}_{2}$, ocupando sítios 
livres. O mecanismo responsável pela emergência das oscilações é descrito a seguir em três etapas distintas: etapa $(2 \rightarrow 3)$ : em baixos potenciais, monóxido de carbono e formato competem por sítios livres, aumentando o recobrimento de $\mathrm{CO}_{\mathrm{L}}$ e diminuindo de $\mathrm{HCOO}_{\mathrm{ad}}$, a combinação dos processos de adsorção resulta no aumento do potencial a fim de manter a corrente total constante; etapa $(3 \rightarrow 4)$ : em torno de $0,80 \mathrm{~V}$ inicia-se o processo de oxidação da superfície, favorecendo a formação de $\mathrm{OH}_{\mathrm{ad}}$. Este promove a inibição da reação (r2) e favorece a oxidação de $\mathrm{CO}_{\mathrm{L}}$ via mecanismo de Langmuir-Hinshelwood. Neste sentido, $\theta_{\mathrm{COL}} \mathrm{e}$ $\theta_{H C C O}$ diminuem rapidamente atingindo valores de 0,25 e 0,10 monocamadas, respectivamente; etapa $(1 \rightarrow 2)$ : o processo de reativação é notório pela diminuição explosiva da cobertura $\theta_{O H}$ de 0,30 à 0,001 , ocasionado pelo consumo na reação (r5). Note que neste curto intervalo de tempo a cobertura de $\mathrm{HCOO}_{\mathrm{ad}}$ aumenta imediatamente à disponibilidade de sítios livres gerados pela reativação superficial. Dessa forma, observa-se uma queda brusca do potencial, retornando ao ponto inicial do ciclo. É importante salientar que o mecanismo oscilatório apresentado aqui difere, de modo geral, ao apresentado por Mukouyama et al. ${ }^{[52]}$ devido à inclusão da etapa (r4), entretanto tais divergências não interferem no processo de análise global utilizada neste trabalho. Maiores detalhes serão abordados na seção 5.2.3.

Sob o ponto de vista dinâmico, a emergência e o fim das oscilações obedecem de modo geral às seqüências de bifurcações ${ }^{[42,43]}$ (i.e. mudança qualitativa do sistema) encontradas corriqueiramente em dinâmica não-linear. Exemplos como a bifurcação de Hopf subcrítica e homoclínica são mostradas na Figura 8. 


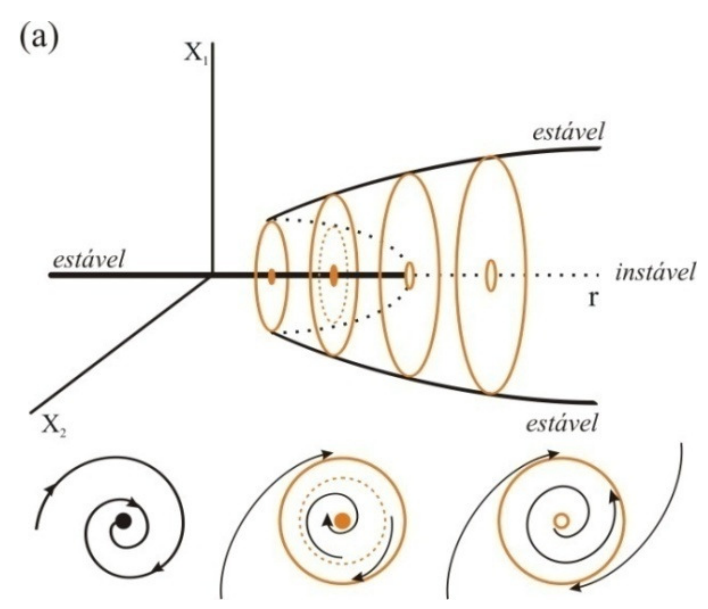

(b)

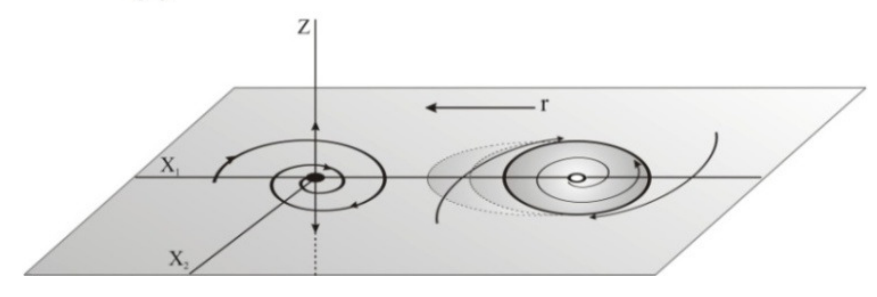

Figura 8: Esquema ilustrativo da (a) bifurcação de Hopf subcrítica e (b) bifurcação homoclínica.

O nascimento das oscilações durante a EAF acontece pela bifurcação de Hopf subcrítica. Esta bifurcação é caracterizada pelo nascimento de forma explosiva das oscilações quando variado um parâmetro e facilmente reconhecida devido à histerese, vide Figura 8a. Com aumento de um parâmetro de bifurcação $r$, o sistema perde a estabilidade do estado estacionário pelo nascimento de um ciclo limite instável. Após a colisão entre o ciclo limite instável com o estado estacionário estável existe a formação de um ciclo limite estável o que caracteriza o nascimento das oscilações. Na Figura 8b, observa-se a bifurcação do tipo homoclínica. Quando existe o toque entre o ciclo limite e um ponto de sela no espaço de fase a órbita torna-se homoclínica, ou seja, as trajetórias do ciclo limite são deformadas devido ao efeito atrativo ou repulsivo do ponto de sela. Neste caso, é comum a variação da amplitude e freqüência oscilatória na bacia de atração do ponto de sela. Ademais, se o aumento do 
parâmetro $r$ for demasiado, há a colisão entre o ciclo limite e o ponto de sela caracterizando a destruição das oscilações. Este tipo de bifurcação é usualmente encontrada durante a EAF onde o fim das oscilações acontece quando o ciclo limite colide com um ponto estacionário relativo ao ramo associado à reação de desprendimento de oxigênio em altos valores de potencial $^{[64]}$.

De modo geral, as simulações reproduziram fielmente as observações experimentais, capturando as características essenciais encontradas durante a eletro-oxidação de ácido fórmico, o que destaca além da qualidade dos parâmetros atribuídos, o modelo proposto. Simulações serão conduzidas a fim de auxiliar a interpretação dos resultados e propostas mecanísticas serão formuladas para o entendimento do comportamento de (sobre)compensação de temperatura. 


\section{Resultados e Discussões}

\subsection{Resultados}

Observa-se na Figura 9 os perfis voltamétricos obtidos à $5 \mathrm{mV} \mathrm{s}^{-1}$ durante a EAF sobre platina policristalina em ácido sulfúrico e sob diferentes temperaturas. De modo geral, as principais características tais como a presença de um pico de oxidação na varredura positiva entre 0,80 e $1,00 \mathrm{~V}$ e a região de reativação na varredura negativa dando início em torno de 0,90 V são perfeitamente discerníveis e estão em concordância com a literatura corrente ${ }^{[45]}$.

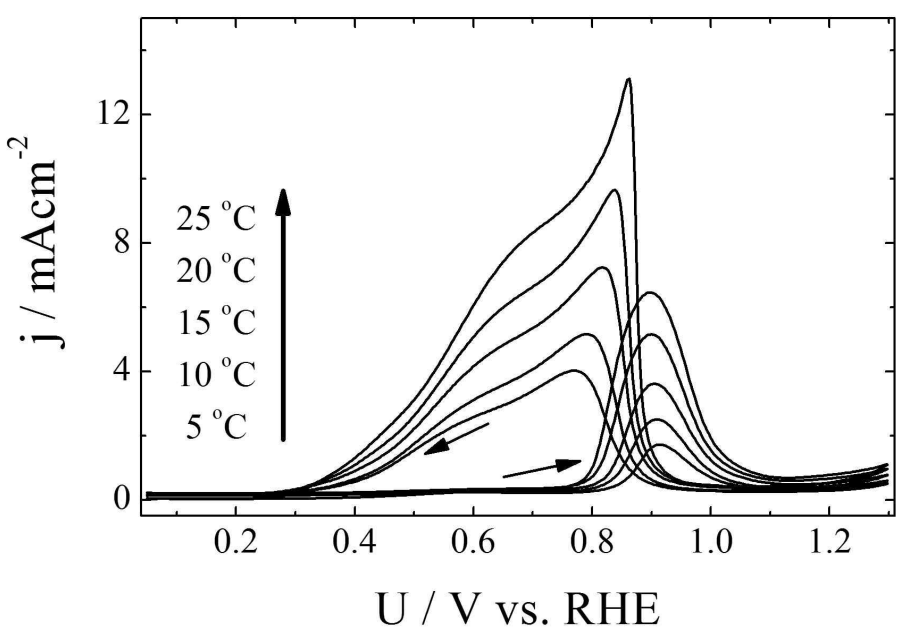

Figura 9: Voltamogramas cíclicos durante a EAF sobre platina policristalina à $\mathrm{dU} / \mathrm{dt}=5 \mathrm{mV} \mathrm{s}^{-1}$ em diferentes temperaturas. $\left[\mathrm{H}_{2} \mathrm{SO}_{4}\right]=0,1 \mathrm{~mol} \mathrm{~L}^{-1}$ e $[\mathrm{HCOOH}]$ $=0,6 \mathrm{~mol} \mathrm{~L}{ }^{-1}$.

O efeito característico encontrado com o aumento da temperatura é o aumento das densidades de correntes voltamétricas e um ligeiro decréscimo da separação entre os picos da varredura positiva e negativa. $\mathrm{O}$ efeito da temperatura nos perfis voltamétricos dados na Figura 9 pode ser descrito em termos da energia de ativação aparente, $E_{a}{ }^{a p p}$, calculada pela equação de Arrhenius em curvas: lnj vs. 1/T. Neste sentido, a energia de ativação aparente 
reflete a soma de todas as contribuições para a reação de eletro-oxidação em certo potencial. Focalizando na janela de potenciais entre 0,80 e $0,90 \mathrm{~V}$ na varredura positiva, os valores estimados de $E_{a}^{a p p}$ são mostrados na Figura 10.

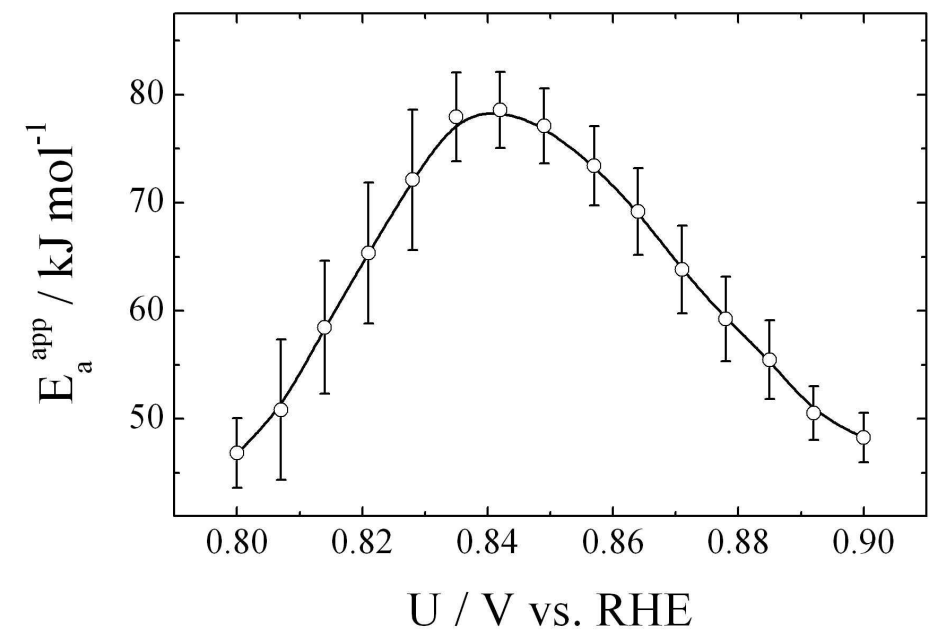

Figura 10: Energias de ativação aparente em diferentes potenciais. Os valores foram obtidos a partir da varredura positiva nos voltamogramas cíclicos, vide Figura 9.

Observa-se um aumento da energia de ativação aparente de $47 \mathrm{~kJ} \mathrm{~mol}^{-1}$ à $0,80 \mathrm{~V}$ até um máximo de $79 \mathrm{~kJ} \mathrm{~mol}^{-1}$ à $0,84 \mathrm{~V}$. Em altos potenciais, $E_{a}^{a p p}$ tende a decrescer com o potencial e alcança $48 \mathrm{~kJ} \mathrm{~mol}^{-1}$ à $0,90 \mathrm{~V}$. O intervalo de potencial 0,80 à $0,90 \mathrm{~V}$ foi escolhido porque corresponde ao estágio inicial de oxidação do ácido fórmico sob condições voltamétricas (c.f. Figura 9). Experimentos em temperaturas mais altas (até $45{ }^{\circ} \mathrm{C}$, não mostrados) resultaram em uma energia de ativação aparente de aproximadamente $32 \mathrm{~kJ} \mathrm{~mol}^{-1}$ no intervalo de 0,85 à $0,90 \mathrm{~V}$.

Cinética oscilatória na EAF pode ser observada em ambos os modos de controle, isto é galvanostático ou potenciostático, sendo que no segundo caso faz-se necessária a inserção de uma resistência externa acoplada entre o eletrodo de trabalho e o potenciostato. As oscilações mostradas aqui foram obtidas sob controle galvanostático. Neste caso, a corrente aplicada 
reflete o fluxo de elétrons entre a interface sólido/líquido e é uma medida do afastamento do equilíbrio do sistema, similarmente à voltagem aplicada e à resistência externa em modo potenciostático $^{[65]}$. Uma visão geral da dinâmica oscilatória é dada na Figura 11 em termos de oscilações de potencial obtidas durante varredura galvanodinâmica $\left(\mathrm{dI} / \mathrm{dt}=5 \mu \mathrm{A} \mathrm{s}{ }^{-1}\right)$ em diferentes temperaturas.

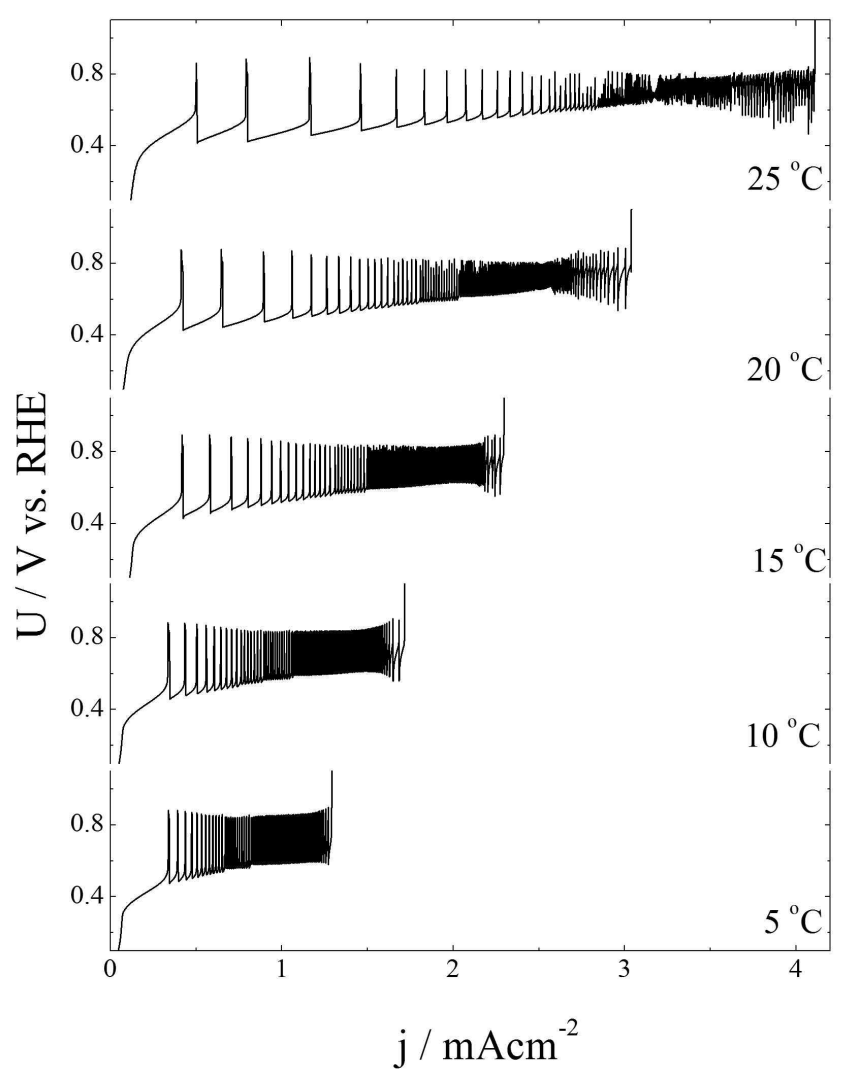

Figura 11: Oscilações de potencial durante a EAF sobre Pt policristalina em controle galvanodinâmico $\left(\mathrm{dI} / \mathrm{dt}=5 \mu \mathrm{A} \mathrm{s}^{-1}\right)$ sob diferentes temperaturas. $\left[\mathrm{H}_{2} \mathrm{SO}_{4}\right]$ $=0,1 \mathrm{~mol} \mathrm{~L}^{-1}$ e $[\mathrm{HCOOH}]=0,6 \mathrm{~mol} \mathrm{~L}^{-1}$.

As oscilações de potencial nascem em baixos valores de correntes via bifurcação de Hopf subcrítica e desaparecem em altos valores de correntes através da bifurcação homoclínica, onde o ciclo limite colide com o ponto estacionário referente ao ramo de desprendimento de oxigênio, encontrado também em outros sistemas similares ${ }^{[66]}$. A 
característica mais evidente na Figura 11 é a tendência de que quanto maior a temperatura, menor é a frequiência oscilatória. Entretanto, a natureza não-estacionária dos experimentos não permitiu uma análise rigorosa, adiando a possível discussão. Um ponto importante a ser notado na Figura 11 é a dependência do tamanho da região oscilatória, $S_{\text {osc }}$, com a temperatura. Um aumento linear de $S_{\text {osc }}$ com a temperatura é observado neste conjunto de dados.

A comparação da dinâmica oscilatória sob condição estacionária (i.e. corrente fixa) em diferentes temperaturas requer a consideração da mudança de $S_{\text {osc }}$ com a temperatura. Levando em conta este efeito, a corrente aplicada foi normalizada de acordo com a equação,

$$
I_{N}^{T}=\frac{j_{o s c}^{T}-j_{o s c, i}^{T}}{j_{o s c, f}^{T}-j_{o s c, i}^{T}}
$$

onde $j_{o s c}^{T}$ é a densidade de corrente aplicada, $j_{o s c, i}^{T}$ e $j^{T}$ osc, $f$ são as correntes inicial e final que define a região de oscilatória de potencial, respectivamente. $j^{T}{ }_{o s c, i}$ e $j^{T}{ }_{o s c, f}$ são estimados através da varredura galvanodinâmica. Este procedimento de normalização permite a comparação das séries temporais de potencial obtidas a diferentes temperaturas para uma dada corrente aplicada. Oscilações típicas para $I_{N}^{T}=0,33$ são mostrados na Figura 12. 


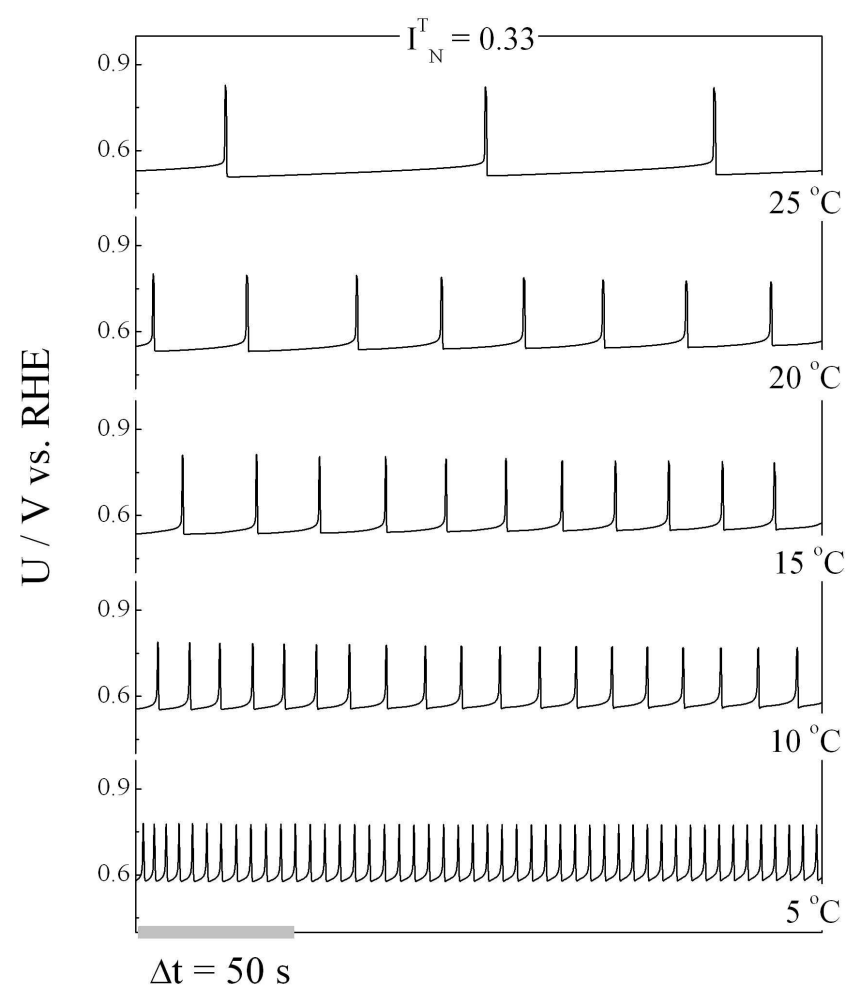

Figura 12: Séries temporais de potencial durante a EAF sobre platina policristalina em diferentes temperaturas com $\mathrm{I}^{\mathrm{T}}{ }_{\mathrm{N}}=0,33 .\left[\mathrm{H}_{2} \mathrm{SO}_{4}\right]=0,1 \mathrm{~mol} \mathrm{~L}^{-1} \mathrm{e}$ $[\mathrm{HCOOH}]=0,6 \mathrm{~mol} \mathrm{~L}^{-1}$.

De modo geral a morfologia das oscilações permanece independente da temperatura e além de pequenas mudanças na amplitude, o ponto principal a ser abordado aqui é que as oscilações tornam-se mais lentas com o aumento da temperatura. De fato, períodos de 5 e 95 segundos foram observados à 5 e $25^{\circ} \mathrm{C}$, respectivamente. Para esta janela de temperatura mostrada, o número de oscilações de potencial é $48,19,11,8$ e 3 à $5,10,15,20$ e $25^{\circ} \mathrm{C}$, respectivamente. Outro conjunto de séries temporais obtidas à para $I^{T}{ }_{N}=0,83$ é mostrado na Figura 13. 


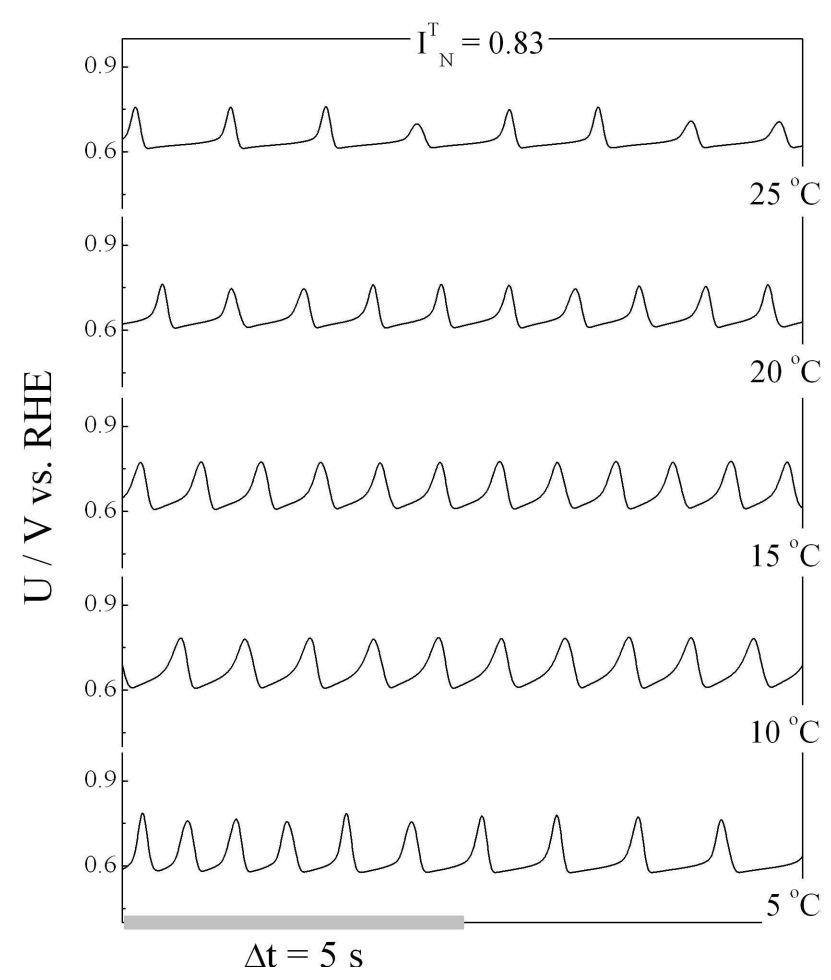

Figura 13: Séries temporais de potencial durante a EAF sobre platina policristalina em diferentes temperaturas com $\mathrm{I}^{\mathrm{T}}{ }_{\mathrm{N}}=0,83 .\left[\mathrm{H}_{2} \mathrm{SO}_{4}\right]=0,1 \mathrm{~mol} \mathrm{~L}^{-1} \mathrm{e}$ $[\mathrm{HCOOH}]=0,6 \mathrm{~mol} \mathrm{~L}{ }^{-1}$.

Como na Figura 12, a forma das oscilações é ligeiramente similar e insensível à temperatura nesta corrente. Entretanto, as oscilações são menos agudas e mais rápidas neste caso. Surpreendentemente, neste conjunto o período das oscilações depende fracamente da temperatura, com intervalo de período de 0,87 à 1,36 segundos para as diferentes temperaturas. O número de oscilações de potencial no intervalo de tempo dado é 10 (na verdade, $10,10,12,10$ e 8 , com o aumento da temperatura).

Uma importante diferença na morfologia das oscilações mostradas nas Figuras 12 e 13 é que em correntes altas ambas as transições ativo/passivo e passivo/ativo são menos íngremes, os quais resultam em uma separação mais discernível dessas transições nas séries mostradas na Figura 13. De modo geral, a forma das oscilações é muito similar para uma dada corrente normalizada e diferentes temperaturas, o qual suporta a validação do procedimento 
de normalização adotado. Mudanças na morfologia das oscilações têm sido reportadas também no sistema peróxido de hidrogênio/tiosulfato/sulfito ${ }^{[35]}$. Especificamente, o aumento da temperatura de 25 à $33^{\circ} \mathrm{C}$ acelerou a transição de baixo à alto $\mathrm{pH}$, no entanto o período oscilatório e a transição de alto à baixo pH permaneceram inalterados.

Um resumo dos resultados experimentais tais como o período e amplitude oscilatória em diferentes temperaturas e densidades correntes aplicadas são dados na Figura 14.
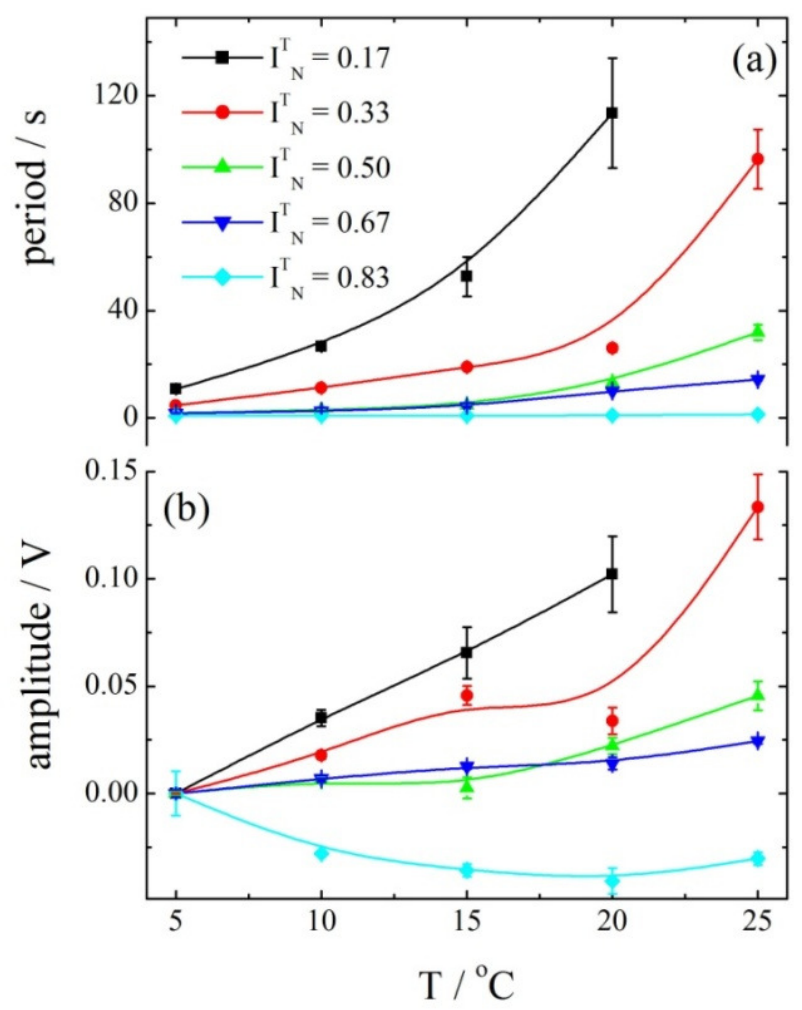

Figura 14: (a) Período e (b) amplitude (normalizada em $A^{T}-A^{5^{\circ} \mathrm{C}} / \mathrm{V}$ vs. RHE) oscilatória em função da temperatura para diferentes correntes normalizadas durante a EAF sobre platina policristalina.

Período e amplitude foram calculados utilizando-se pelo menos oito oscilações e a incerteza é dada pela barra de erros. Em ambos os casos, a resposta é fortemente dependente da temperatura e da corrente aplicada. Como mostrado na Figura 14a, o aumento de período acompanhando o incremento de temperatura é mais pronunciado para baixas correntes 
aplicadas e tornam-se menos evidentes em altas correntes. $\mathrm{O}$ efeito da temperatura e corrente aplicada na amplitude oscilatória é mais complicado, Figura 14b. Para a menor corrente investigada, a amplitude aumenta linearmente com a temperatura. Este aumento torna-se menos pronunciado para altas correntes e finalmente um ligeiro decréscimo é observado no maior valor de corrente estudado.

Com a finalidade de obter maiores informações sobre o comportamento de (sobre)compensação de temperatura observado experimentalmente neste trabalho, foi proposto um modelo na seção 4 para as etapas elementares durante a EAF. Simulações dos espectros de freqüências em regime galvanostático e potenciostático sob diferentes temperaturas foram obtidas a partir da transformada de Fourier (fast fourier transform, FFT) e são mostradas na Figura 15. As simulações foram conduzidas num amplo intervalo de parâmetros e apenas (sobre)compensação de temperatura foi observada. 


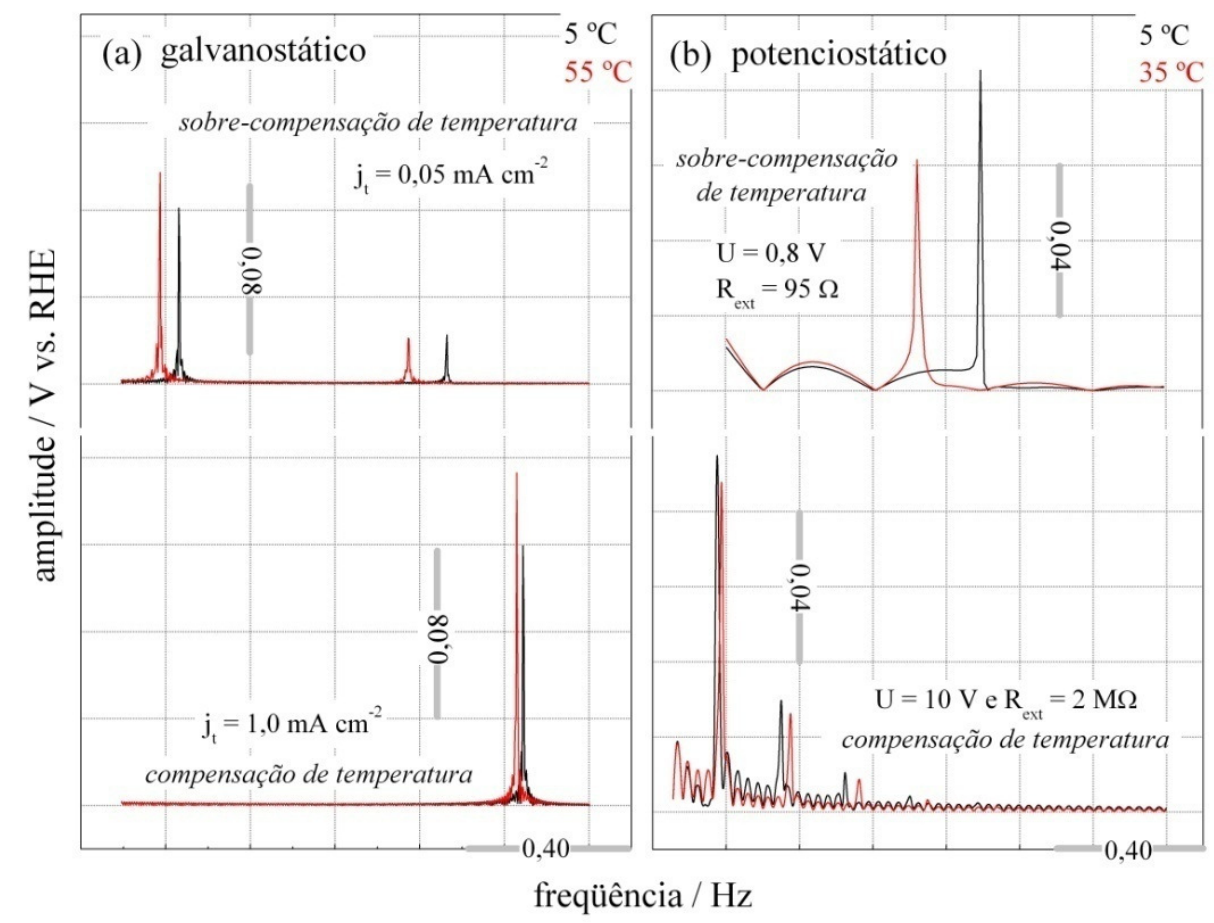

Figura 15: Espectros de freqüências simulados a partir do modelo proposto durante a EAF sobre platina, sob regime (a) galvanostático e (b) potenciostático. Parâmetros: $\mathrm{k}_{1}=3,0.10^{3} \mathrm{~L} \mathrm{~mol}^{-1} \mathrm{~s}^{-1}, \mathrm{k}_{2}=4,0.10^{2} \mathrm{~s}^{-1}, \mathrm{k}_{3}=1,0.10^{2} \mathrm{~L} \mathrm{~mol}^{-1} \mathrm{~s}^{-1}, \mathrm{k}_{4}=$ $3,0.10^{-2} \mathrm{~L} \mathrm{~mol}^{-1} \mathrm{~s}^{-1}, \mathrm{k}_{-4}=3,0.10^{5} \mathrm{~s}^{-1}$.

As condições de sobre-compensação e compensação de temperatura são atingidas variando-se os parâmetros: (a) corrente aplicada entre 0,05 à $1,0 \mathrm{~mA} \mathrm{~cm}^{-2}$ (i.e modo galvanostático) e temperatura entre 5 à $55^{\circ} \mathrm{C}$, (b) potencial aplicado de 0,8 à $10 \mathrm{~V}$ e resistência externa entre 95 à $2.10^{6} \Omega$ (i.e. modo potenciostático) e temperatura na faixa de 5 à $35^{\circ} \mathrm{C}$. É necessário salientar que os parâmetros utilizados para o cálculo da Figura 15b não são necessariamente iguais ao mostrado na Tabela I e são omitidos no presente trabalho. Neste caso, o espectro de freqüências dado em modo potenciostático é utilizado apenas como referência em comparação às frequiências obtidas em regime galvanostático. Observa-se, notavelmente, que ambas as formas de controle exibiram o comportamento de (sobre)compensação de temperatura, Figura 15a e b. Em baixas correntes ou potencial aplicado, o aumento da temperatura resultou na diminuição da freqüência oscilatória, 
enquanto que em altas correntes ou potencial, a freqüência oscilatória permaneceu inalterada. Neste sentido, sobre-compensação foi encontrada em condições de baixas correntes e potenciais aplicados e compensação de temperatura é apenas observada em condições suficientemente afastadas do equilíbrio termodinâmico. Outro aspecto importante a ser notado é que em regime galvanostático o modelo capturou a tendência geral observada nos experimentos eletroquímicos de que quanto maior a corrente aplicada maior é a freqüência das oscilações, e a amplitude oscilatória é maior em temperaturas mais elevadas.

Embora o modelo tenha representado de forma quantitativa os valores dos recobrimentos e potencial observados experimentalmente (vide, seção 4), foi capaz de reproduzir apenas qualitativamente o fenômeno de (sobre)compensação de temperatura. Deve-se notar que a mudança de temperatura resultou em uma variação sutil da frequiência e amplitude sob os diferentes modos de controle. Este problema pode estar relacionado com as condições de contorno utilizadas, especificamente a independência de $k_{i}$ em função da temperatura o que não condiz com a equação usual de Arrhenius. Assim, considerações mecanísticas sobre o efeito da temperatura na EAF serão embasadas em diferentes relações entre recobrimento das espécies adsorvidas em função do período oscilatório e corrente aplicada. 


\subsection{DISCUSSÕES}

\subsection{1 (SOBRE)COMPENSAÇÃO DE TEMPERATURA NO PERÍODO OSCILATÓRIO}

Em um sistema oscilatório pode-se definir o coeficiente de temperatura em termos do período oscilatório $P$,

$$
Q_{10}=\frac{P_{T}}{P_{T+10}}
$$

ou, o equivalente à Equação 5.2.1.1, para um intervalo de temperatura genérico,

$$
q_{10}=\left(\frac{P_{T_{1}}}{P_{T_{2}}}\right)^{\frac{10}{\left(T_{2}-T_{1}\right)}}
$$

A energia de ativação global para um sistema oscilatório pode ser calculado em termos da freqüência oscilatória $f(=1 / P)^{[67]}$,

$$
f=A e^{-E_{a}^{t} / R T}
$$

ou similarmente à Equação 1.1.3, em termos do coeficiente de temperatura $q_{10}$.

Em contraste aos osciladores químicos mencionados anteriormente ${ }^{[34,35]}$, oscilações na oxidação eletrocatalítica de ácido fórmico sobre platina ocorreram num amplo intervalo de temperatura e foram estudados aqui entre 5 à $25{ }^{\circ} \mathrm{C}$. O coeficiente de temperatura $q_{10}$ calculado via Equação 5.2.1.2 para diferentes temperaturas é dado na Tabela II. 
Tabela II: Valores de $q_{10}$ obtidos para diferentes intervalos de temperatura e correntes aplicadas.

\begin{tabular}{cccccc}
\hline$\Delta T{ }^{o} C$ & $I^{T}{ }_{N}=0,17$ & $I^{T}{ }_{N}=0,33$ & $I^{T}{ }_{N}=0,50$ & $I^{T}{ }_{N}=0,67$ & $I^{T}{ }_{N}=0,83$ \\
\hline $20-25$ & --- & 0,13 & 0,25 & 0,43 & 0,76 \\
$15-20$ & 0,22 & 0,53 & 0,13 & 0,18 & 0,78 \\
$10-15$ & 0,26 & 0,34 & 0,41 & 0,35 & 1,16 \\
$5-10$ & 0,16 & 0,18 & 0,40 & 0,50 & 0,92 \\
$5-25$ & 0,22 & 0,25 & 0,24 & 0,33 & 0,96 \\
\hline
\end{tabular}

$\mathrm{Na}$ última linha da Tabela II foi calculado valores de $q_{10}$ para todo intervalo de temperatura em estudo $\left(5\right.$ à $\left.25^{\circ} \mathrm{C}\right)$, ou seja, na mesma faixa de temperatura utilizada para calcular a energia de ativação aparente via Equação 1.1.3. Em geral, para um dado intervalo de temperatura, $q_{10}$ tende a aumentar com a corrente aplicada. Como mencionado na seção 1.1, sobre-compensação de temperatura reflete uma situação onde o aumento da temperatura resulta em um decréscimo na taxa reacional ou, num aspecto oscilatório, o aumento do período das oscilações. Como mostrado na Tabela II esta situação aparece para a maioria dos casos, i.e. $q_{10}<1$. Compensação de temperatura do período oscilatório ou, a independência do período em relação à temperatura, é observada em altas correntes e em baixos intervalos de temperatura. Em modo de comparação, coeficientes de temperatura de osciladores circadianos usualmente permanecem no intervalo de 0,8 e $1,2^{[16]}$. Coeficientes de temperatura entre 0,67 e 1,80 foram obtidos por Rábai e colaboradores $^{[36]}$ para a clássica reação de Bray. Os experimentos foram conduzidos em regime de batelada num intervalo de temperatura de 10 ${ }^{\circ} \mathrm{C}$, observando que os valores de $q_{10}$ são fortemente dependentes da concentração de alguns reagentes.

Uma questão que surge na análise do efeito de compensação de temperatura em sistemas químicos é se há um mecanismo de compensação real ou se o sistema é 
simplesmente insensível à temperatura. Os resultados experimentais de voltametria cíclica mostrados nas Figuras 9 excluem essa segunda possibilidade. Como recentemente reportado por Cohen et al. ${ }^{[68]}$ a energia de ativação em processos como EAF é função (a) do potencial, (b) das rotas reacionais em determinado potencial e (c) do recobrimento superficial relativo tal como ânions adsorvidos, intermediários de reação e óxidos superficiais. Neste trabalho ${ }^{[68]}$, os autores estudaram em detalhes o efeito da temperatura durante a eletro-oxidação de metanol sobre platina policristalina em diversas condições experimentais e acharam uma dependência da energia de ativação em relação ao potencial similar ao encontrado na Figura 10. Seguindo a referente interpretação, a maior energia de ativação encontrada aproximadamente em $0,84 \mathrm{~V}$ é de grande interesse porque as contribuições da superfície no processo mencionado são minimizadas. Então, a energia de ativação aparente de aproximadamente $80 \mathrm{~kJ} \mathrm{~mol}{ }^{-1}$ observada aqui pode ser utilizada como sendo representativa do processo global da EAF sob condições não oscilatórias. Portanto, o coeficiente de temperatura próximo de 1, e conseqüentemente uma energia de ativação próxima de 0 , observada no estado oscilatório não pode ser simplesmente resultado de uma pequena dependência da cinética global em relação à temperatura. Argumento similar tem sido utilizado também por Rábai e Hanazaki com a verificação de compensação de temperatura em sistemas homogêneos peróxido de hidrogênio/tiosulfato/sulfito ${ }^{[34]}$.

\subsubsection{AMPLITUDE OSCILATÓRIA}

O período e amplitude oscilatória para diferentes temperaturas e correntes aplicadas foram apresentados na Figura 14. O primeiro ponto notável é que ambos, período e amplitude, são fortemente dependentes da temperatura e correntes aplicadas. Observou-se que em (a) 
baixas correntes aplicadas o aumento da temperatura resultou em um aumento do período e amplitude oscilatória e em (b) altas correntes aplicadas ambos, período e amplitude, foram quase independentes da temperatura. Diferentes estados foram observados entre estas duas situações limites para diferentes correntes aplicadas, e em uma tendência geral, foi mostrado que sobre-compensação de temperatura é favorecida em baixas correntes aplicadas e que os coeficientes de temperaturas aumentam com o aumento da corrente aplicada.

Apesar de uma vasta literatura sobre compensação de temperatura no período oscilatório em sistemas biológicos, discussões considerando a dependência da amplitude das oscilações com a temperatura é menos comum e os resultados menos conclusivos. De fato, o efeito da temperatura na amplitude oscilatória em alguns sistemas que apresentam compensação de temperatura mostra uma tendência pouco clara e dependem das propriedades periódicas sob um caráter bioquímico do sistema. Lakin-Thomas et al. ${ }^{[69]}$ propuseram um modelo para sistemas que apresentam compensação de temperatura no qual a amplitude das oscilações aumentam com a temperatura afim de manter a frequiência oscilatória constante. A "hipótese da amplitude" de Lakin-Thomas et al. ${ }^{[69]}$ foi utilizada para explicar a dinâmica de osciladores circadianos no fungo Neurospora crassa. O aumento da amplitude na produção periódica da proteína FRQ no marca-passo circadiano da $N$. crassa sob regime de compensação de temperatura foi observado experimentalmente ${ }^{[70]}$ e também capturado em um modelo simples ${ }^{[11]}$. Do lado puramente químico, o aumento da amplitude oscilatória com a temperatura, como sugerido por Lakin-Thomas et al. ${ }^{[69]}$, tem sido observado na clássica reação de Bray em batelada ${ }^{[36]}$. Pittendrigh et al. ${ }^{[71]}$ estudaram diferentes aspectos da amplitude no marca-passo circadiano da Drosophila e observaram que ao contrário do período, a amplitude do marca-passo é fortemente dependente da temperatura. Os resultados reportados para a Drosophila ${ }^{[71]}$ diferem aos reportados para a Neurospora ${ }^{[69]}$ em termos da dependência da temperatura com a amplitude oscilatória: o aumento da temperatura resultou 
em um decréscimo da amplitude no primeiro caso, e um aumento de amplitude no segundo. Entretanto, os autores evidenciam a importância do entendimento do efeito das restrições impostas pelo ambiente na amplitude oscilatória e sugerem que a amplitude é uma variável na qual sistemas circadianos sentem os ciclos sazonais ${ }^{[71]}$.

Os resultados obtidos aqui evidenciam uma intricada combinação entre a temperatura e a corrente aplicada na dinâmica oscilatória encontrada durante a EAF sobre platina policristalina. A corrente aplicada através da interface sólido/líquido é uma medida direta do fluxo de elétrons entre o eletrodo metálico e as espécies em solução. Portanto, a corrente aplicada é relatada como um parâmetro de afastamento do equilíbrio termodinâmico como o transporte de massa num reator de fluxo. A influência da posição relativa com respeito ao afastamento do equilíbrio termodinâmico e sua dependência com a temperatura, afetando o período e amplitude oscilatória não têm sido investigadas com profundidade.

Estudando o efeito da temperatura na dinâmica de alguns osciladores de bromato catalisados por cério, Nagy et al. ${ }^{[72]}$ observaram coeficientes de temperatura no intervalo de 2,2 e 3,2 quando o sistema foi operado sob batelada, porém valores de $q_{10}$ entre 1,3 e 1,7 foram observados em um reator com agitação de fluxo contínuo (continous flow stirred tank reactor, CSTR). Embora os autores, reconheceram a importância do papel do fluxo no alcance de compensação de temperatura, o impacto do fluxo na amplitude oscilatória não foi apresentado. Estudos no sistema peróxido de hidrogênio/tiosulfato/sulfito ${ }^{[34]}$ revelaram de modo geral que a amplitude das oscilações decresce gradualmente com o aumento da temperatura. Ademais, o período diminuiu com o aumento do fluxo. Este sistema tem sido sistematicamente estudado e diferentes estados dinâmicos observados. Em alguns casos, a amplitude das oscilações aumentou com a diminuição do fluxo, entretanto, nenhum dado considerando o papel do fluxo na amplitude oscilatória durante compensação de temperatura, foi apresentado. Observações similares da importância nas condições de fluxo sobre o 
coeficiente de temperatura tem sido reportado por Kovács e Rábai em osciladores de $\mathrm{pH}^{[35]}$. Simulações numéricas mostram um decréscimo na amplitude oscilatória quando existe o aumento da temperatura. Estudando o efeito da temperatura na decomposição oscilatória de peróxido de hidrogênio em solução ácida na presença de iodeto de potássio (reação de Bray), Kovács et al. ${ }^{[36]}$ observaram em experimentos sob CSTR que para certos fluxos, a amplitude oscilatória aumentou para o aumento da temperatura quando compensação de temperatura foi alcançada. Acredita-se que a aparente variedade no efeito da temperatura na amplitude das oscilações, como revisado acima, pode surgir devido ao não reconhecimento da distância do equilíbrio termodinâmico como um parâmetro importante. Como apresentado aqui (e.g. Figura 14b) temperatura pode afetar a amplitude oscilatória em diferentes modos dependendo da distância do equilíbrio.

\subsubsection{CONSIDERAÇÕES MECANÍSTICAS}

Cinética oscilatória durante a eletro-oxidação de ácido fórmico sobre platina tem sido usualmente observada, sendo resultado da presença de uma resistência diferencial negativa em uma curva estacionária corrente/potencial em forma de "N" ${ }^{[38]}$. O fenômeno tem sido explicado em termos da interação dos ciclos de retro-alimentação positivo e negativo no potencial da dupla camada. Em termos das espécies adsorvidas oscilantes, o recobrimento das espécies oxigenadas oscila de modo sincronizado com o potencial ${ }^{[60]}$. Ademais, o mesmo comportamento é observado para monóxido de carbono linear e formato adsorvido durante oscilações em regime galvanostático ${ }^{[49]}$.

A origem mecanística do comportamento anti-Arrhenius reportado neste trabalho pode ser entendida como um acoplamento entre diferentes rotas reacionais em regime oscilatório 
em vez de uma fraca dependência com a temperatura. Neste sentido, torna-se indispensável o conhecimento das possíveis etapas reacionais que governam os ciclos de retro-alimentação. Para o melhor entendimento, a Figura 16 representa de modo esquemático três etapas que constituem um ciclo no espaço de fase.

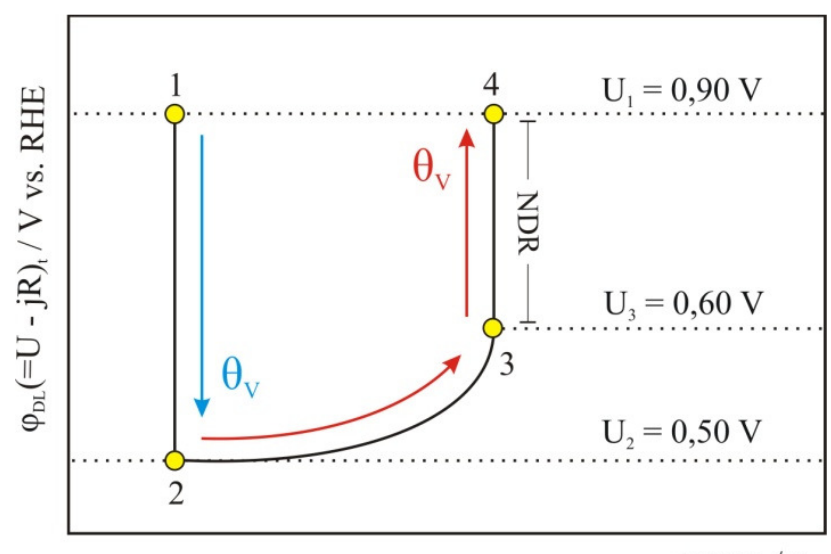

tempo / s

Figura 16: Esquema ilustrativo das oscilações de potencial dividido em três etapas $1 \rightarrow 2,2 \rightarrow 3$ e $3 \rightarrow 4$.

Os resultados podem ser discutidos com embasamento experimental já desenvolvido por Owasa e colaboradores ${ }^{[49-51]}$ e algumas indicações sugeridas pelo modelo proposto. Assim os ciclos de retro-alimentação positivo (vermelho) e negativo (azul) podem ser relacionados com a variação do recobrimento total ou vacante na superfície metálica. (a) ciclo de retroalimentação positivo "etapa $(2 \rightarrow 3)$ : resume-se no processo de adsorção de monóxido de carbono e formação/remoção do recobrimento de formato entre 0,50 e 0,60 V. Menor contribuição para esta etapa pode ser identificada como a adsorção de ânions (bi)sulfato; etapa $(3 \rightarrow 4)$ : neste ponto em $0,60 \mathrm{~V}$, existe o consumo de monóxido de carbono através da reação com espécies oxigenadas, como $\mathrm{H}_{2} \mathrm{O}_{a d}$ previamente adsorvida, o que libera sítios ativos facilitando a adsorção de formato de forma explosiva. Em torno de $0,80 \mathrm{~V}$ a oxidação superficial inicia-se, favorecendo o aumento auto-catalítico do potencial do eletrodo. Neste 
ciclo, $\varphi_{D L}$ aumenta a fim de compensar o aumento da cobertura total, mantendo a corrente aplicada constante." (b) ciclo de retro-alimentação negativo "etapa $(1 \rightarrow 2)$ : ao atingir potencial aproximado de $0,90 \mathrm{~V}$, ocorre o processo de desativação superficial, gerando de forma auto-catalítica sítios superficiais vacantes. Neste caso, o mecanismo fundamenta-se na redução das espécies oxigenadas $\left(\mathrm{H}_{\mathrm{x}}\right) \mathrm{O}_{\mathrm{ad}}$, reação de oxidação entre $\mathrm{CO}_{\mathrm{ad}}+\left(\mathrm{H}_{\mathrm{x}}\right) \mathrm{O}_{\mathrm{ad}}$ e decomposição oxidativa de $\mathrm{HCOO}_{\mathrm{ad}}$, ambos, formando $\mathrm{CO}_{2}$. Com a liberação dos sítios superficiais, $\varphi_{D L}$ decai de forma brusca, novamente para manter a corrente aplicada constante.

Observa-se que o mecanismo descrito afasta-se ligeiramente ao discutido no modelo proposto. A diferença ocorre ao assumir que apenas $\mathrm{OH}_{\mathrm{ad}}$ é gerado como espécie oxigenada o que torna natural o deslocamento da NDR para valores maiores de potencial, especificamente 0,80 à 0,90 V. Experimentalmente, Osawa e colaboradores ${ }^{[49]}$ indicam o aumento deliberado de formato como responsável do aumento auto-catalítico do potencial (i.e. origem da NDR), inibindo sua própria decomposição. Esta premissa pode ser questionada devido à importância da formação das espécies oxigenadas no processo de reativação superficial ${ }^{[62]}$ e dos valores de potencial em torno de $0,90 \mathrm{~V}$ encontrados experimentalmente neste trabalho. Ademais, variações em torno do recobrimento de formato de 0,1 e 0,02 obtidos através de $\operatorname{experimentos}^{[49]}$ e simulações ${ }^{[52]}$, respectivamente, são suficientemente pequenas para um aumento de 0,20 ou $0,30 \mathrm{~V}$ no potencial do eletrodo. Note que o processo de reativação superficial está intimamente ligado ao período oscilatório o que torna a inclusão da reação (r4) importante para o entendimento das etapas reacionais presentes nos ciclos de retroalimentação.

Carbonio et al. ${ }^{[73]}$ estudando o efeito da temperatura durante a eletro-oxidação de metanol (EOM) sobre platina policristalina, observaram que para uma dada temperatura, o afastamento do equilíbrio termodinâmico (i.e. corrente aplicada) não resultou em uma mudança significativa no período oscilatório, apenas um acréscimo na amplitude foi relatada. 
Ademais, comportamento usual de Arrhenius foi encontrado em toda região de parâmetros estudados, entre 5 à $35^{\circ} \mathrm{C}$. Energia de ativação aparente sob diversos modos de controle como, voltamétrico e cronoamperométrico foram calculadas e comparadas sob regime oscilatório, vide Tabela III.

Tabela III: Energia de ativação aparente durante a EOM em diversos modos de operação ${ }^{[73]}$.

\begin{tabular}{cccc}
\hline oscilações de potencial & $60 \pm 3 \mathrm{~kJ} \mathrm{~mol}^{-1}$ & & \\
\cline { 2 - 4 } & $@ \mathrm{U}=0,70 \mathrm{~V}$ & $@ \mathrm{U}=0,75 \mathrm{~V}$ & $@ \mathrm{U}=0,80 \mathrm{~V}$ \\
\hline voltametria cíclica & $69 \pm 9 \mathrm{~kJ} \mathrm{~mol}^{-1}$ & $66 \pm 3 \mathrm{~kJ} \mathrm{~mol}^{-1}$ & $64 \pm 2 \mathrm{~kJ} \mathrm{~mol}^{-1}$ \\
cronoamperometria & $48 \pm 1 \mathrm{~kJ} \mathrm{~mol}^{-1}$ & $47 \pm 1 \mathrm{~kJ} \mathrm{~mol}^{-1}$ & $48 \pm 1 \mathrm{~kJ} \mathrm{~mol}^{-1}$ \\
\hline
\end{tabular}

Observa-se que os valores de energia de ativação sob diversos modos de controle estão num intervalo de 50 à $70 \mathrm{~kJ} \mathrm{~mol}^{-1}$ e corroboram com os resultados encontrados na literatura corrente $^{[68]}$. No entanto, para a EAF as energias de ativação observadas neste trabalho resultam em $47 \mathrm{~kJ} \mathrm{~mol}^{-1}$ para $0,80 \mathrm{~V}$ sob condição voltamétrica (e.g. Figura 10 ) e $-4 \mathrm{~J} \mathrm{~mol}^{-1}$ à - $0,51 \mathrm{~kJ} \mathrm{~mol}^{-1}$ sob regime oscilatório (i.e. $E_{a}{ }^{\text {osc }}$ calculadas para valores de $q_{10}$ entre 0,13 à 0,96, respectivamente, vide Tabela II). Note que a grande diferença entre as energias de ativação obtidas durante a eletro-oxidação de metanol e ácido fórmico, tanto em ordem de magnitude quanto ao sinal, indicam diferentes etapas reacionais que governam o processo de oxidação. Neste sentido, durante a EOM, além de monóxido e dióxido de carbono, formaldeído, ácido fórmico e formato foram encontrados experimentalmente durante eletrooxidação sobre platina em meio ácido ${ }^{[45]}$. Martins et al. ${ }^{[74]}$ por meio da técnica FTIRS in situ determinaram o recobrimento de $\mathrm{CO}_{\mathrm{ad}}$ durante a $\mathrm{EOM}$ sob regime galvanostático em torno de 0,7 monocamadas. Entretanto, não foram capazes de monitorar a variação de $\theta_{C O L}$ durante as 
oscilações de potencial devido a limitações experimentais no uso da configuração de reflexão externa o que torna o sinal menos sensível em relação à técnica ATR-SEIRAS.

Efeito da temperatura durante oscilações de potencial em uma célula à combustível de troca protônica com ânodo PtRu alimentado a partir de uma mistura de $\mathrm{H}_{2}$ e $\mathrm{CO}$, foram reportados por Zhang e Datta ${ }^{[67]}$. Experimentos conduzidos em um intervalo de 32 à $70{ }^{\circ} \mathrm{C}$ resultaram em uma energia de ativação aparente de $60,9 \mathrm{~kJ} \mathrm{~mol}^{-1}$ em regime oscilatório. Note que o valor para a energia de ativação encontrado possui ordem de magnitude similar ao observado por Carbonio et al. ${ }^{[73]}$, vide Tabela III. Baseado em argumentos experimentais e teóricos, os autores concluíram que as oscilações são controladas através de processos superficiais em vez de processos difusionais como a chegada do reagente à superfície metálica. Por meio de simulações numéricas Zhang e Datta ${ }^{[67]}$ revelaram que o recobrimento de monóxido de carbono permanece em torno de 0,98 e oscila com amplitude menor que $1 \%$ deste valor. Corroborando com este cenário, Siegmeier et al. ${ }^{[75]}$ recentemente construíram um modelo genérico para o sistema $\mathrm{PtlH}_{2}, \mathrm{CO}$ e mostraram que durante as oscilações via mecanismo $\mathrm{HN}-\mathrm{NDR}$, o recobrimento de $\mathrm{CO}_{\mathrm{ad}}$ oscilou em torno de 0,65 monocamadas com baixa amplitude. De posse dos dados apresentados sobre as energias de ativação em diversos sistemas, Carbonio et al. ${ }^{[73]}$ concluíram que a possível diferença da influência da temperatura na dinâmica oscilatória de metanol ${ }^{[73]}$ e ácido fórmico ${ }^{[76]}$ é causada pelas reações de construção/remoção do recobrimento de monóxido de carbono em regime oscilatório. Este argumento está perfeitamente de acordo com a Figura 16, vide etapa $(2 \rightarrow 3)$ que corresponde a formação dos recobrimentos de monóxido de carbono e formato, e governam o período oscilatório. Neste sentido, considera-se o período oscilatório como uma função complexa dependentes de várias etapas reacionais,

$$
P:=f\left(k_{1}, k_{2}, \ldots, k_{n}\right)
$$


e, portanto, dependente de parâmetros como os recobrimentos, energias de ativação das etapas elementares e temperatura. Considerando a Equação 5.2.1.3, pode-se relacionar o período oscilatório com a temperatura ${ }^{[11]}$,

$$
\frac{\partial \ln P}{\partial T}=\frac{1}{R T^{2}} \sum_{i=1}^{n} C_{i}^{P} E_{a}^{i}
$$

onde a soma dos coeficientes de controle $C_{i}^{P}$ depende de $k_{i}$ e obedece a seguinte relação,

$$
\sum_{i=1}^{n} C_{i}^{P}=-1
$$

Portanto, é possível obter uma expressão geral do efeito da temperatura no período oscilatório, tal que,

$$
\frac{\partial \ln P}{\partial T}=\frac{1}{R T^{2}} \sum_{i=1}^{n}\left[\left(\frac{\partial P}{\partial \theta_{i}}\right)_{k_{i}}\left(\frac{\partial \theta_{i}}{\partial k_{i}}\right)_{T}\left(\frac{\partial k_{i}}{\partial T}\right)_{\theta_{i}}\right] E_{a}^{i}
$$

O somatório indica que a soma entre os coeficientes de controle contrabalanceados com a soma das energias de ativação de cada etapa reacional, resulta no comportamento usual de Arrhenius caso o resultado seja negativo, sobre-compensação se for positivo e compensação de temperatura se o resultado tender à zero ${ }^{[11]}$.

Embora o processo de EAF sobre platina policristalina envolva apenas duas vias reacionais (i.e. direta e indireta), a análise do processo mecanístico durante as oscilações de potencial é complicada devido à evolução de pelo menos quatro variáveis (i.e. $\varphi_{D L}, \theta_{C O L}$, 
$\left.\theta_{H C O O}, \theta_{O H}\right)$ em função do tempo. Com intuito de simplificar o processo de análise é possível representar a variação dos recobrimentos de $\mathrm{CO}_{\mathrm{ad}}, \mathrm{HCOO}_{\mathrm{ad}}$ e $\mathrm{OH}_{\mathrm{ad}}$, por uma única variável, ou seja, os sítios livres disponíveis ou recobrimento total,

$$
\theta_{t}:=\theta_{t}\left(\theta_{C O_{L}}, \theta_{C O_{B}}, \theta_{H C O O}, \theta_{O H}\right)=\left(1-\theta_{V}\right)
$$

dada pela combinação linear entre os recobrimentos das espécies adsorvidas, vide Equação 4.7. Ainda, é possível diminuir um grau de liberdade considerando apenas o recobrimento médio (i.e. média aritmética entre os máximos e mínimos das oscilações em regime galvanodinâmico), eliminando a variação temporal. Neste caso, considera-se que o recobrimento total médio $\theta_{t}^{m}$ está intimamente ligado à energia de ativação global, $E_{a}^{t}$ calculada em regime oscilatório e a densidade de corrente aplicada, $j_{t}$. A variação do período durante as oscilações de potencial em função da temperatura pode ser escrita como,

$$
\frac{\partial \ln P_{U}}{\partial T}=\frac{1}{R T^{2}}\left[\left(\frac{\partial P_{U}}{\partial \theta_{t}^{m}}\right)_{j_{t}}\left(\frac{\partial \theta_{t}^{m}}{\partial j_{t}}\right)_{T}\left(\frac{\partial j_{t}}{\partial T}\right)_{\theta_{t}^{m}}\right] E_{a}^{t}
$$

A grande característica observada na Equação 5.2.3.6 é que a relação entre o período e a temperatura pode, a princípio, ser desmembrada pelas relações de Maxwell. De posse das seguintes relações, simulações foram realizadas a fim de encontrar mecanisticamente a situação que gera o comportamento de (sobre)compensação de temperatura. Na figura 17 , foram calculados os recobrimentos médios de $\mathrm{CO}_{\mathrm{ad}}, \mathrm{HCOO}_{\mathrm{ad}}, \mathrm{OH}_{\mathrm{ad}}$, total e a velocidade média de decomposição de formato, todos em função da densidade de corrente aplicada. 


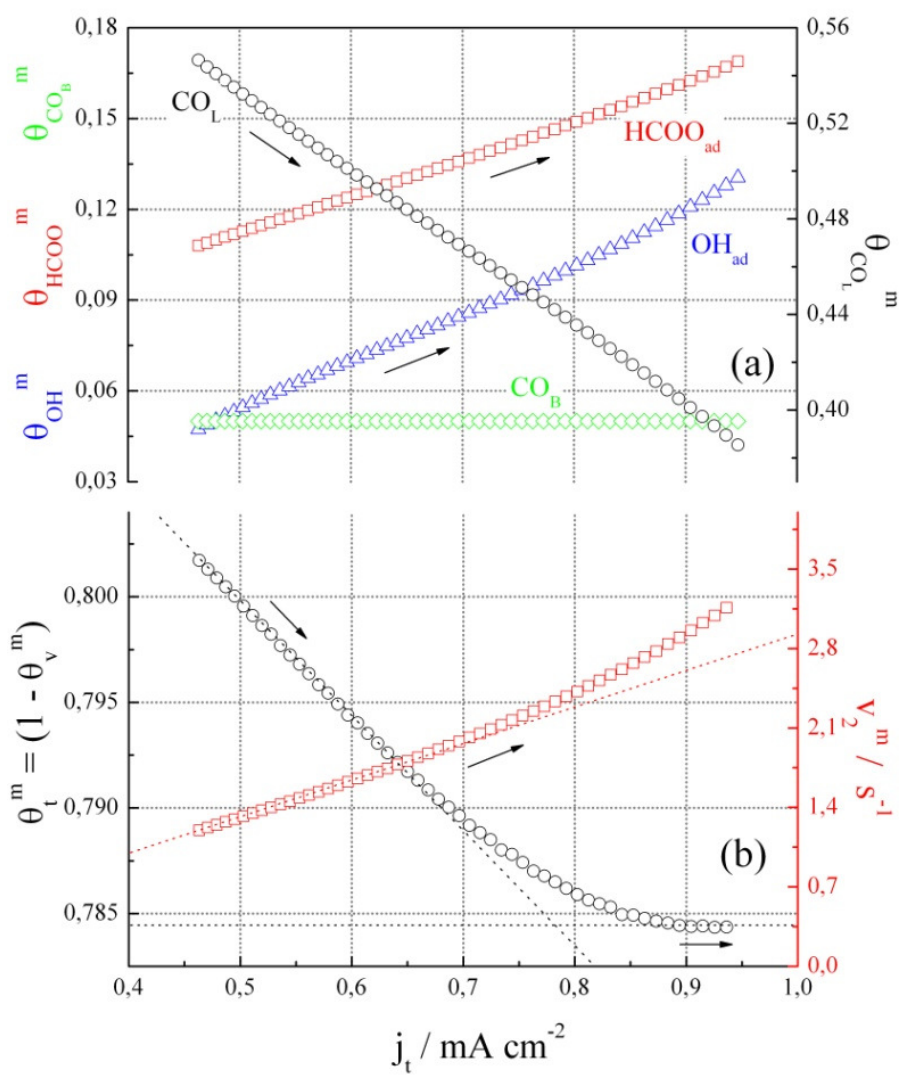

Figura 17: Simulações obtidas a partir do modelo proposto durante a EAF sobre platina para $\mathrm{dI} / \mathrm{dt}=5 \mu \mathrm{A} \mathrm{s}^{-1}$ e $\mathrm{T}=25^{\circ} \mathrm{C}$. (a) variação do recobrimento médio $\theta^{\mathrm{m}} \mathrm{de}$ $\mathrm{CO}_{\mathrm{L}}$ (preto), $\mathrm{CO}_{\mathrm{B}}$ (verde), $\mathrm{HCOO}_{\mathrm{ad}}$ (vermelho), $\mathrm{OH}_{\mathrm{ad}}$ (azul). (b) variação do recobrimento médio de sítios livres, $\theta_{\mathrm{V}}{ }^{\mathrm{m}}$ (preto) e velocidade média da reação (r2), $\mathrm{v}_{2}{ }^{\mathrm{m}}$ (vermelho). Parâmetros: $\mathrm{k}_{1}=1,0.10^{3} \mathrm{~L} \mathrm{~mol}^{-1} \mathrm{~s}^{-1}, \mathrm{k}_{2}=1,1.10^{2} \mathrm{~s}^{-1}, \mathrm{k}_{3}=$ $1,0.10^{2} \mathrm{~L} \mathrm{~mol}^{-1} \mathrm{~s}^{-1}, \mathrm{k}_{4}=3,0.10^{-2} \mathrm{~L} \mathrm{~mol}^{-1} \mathrm{~s}^{-1}, \mathrm{k}_{-4}=2,0.10^{5} \mathrm{~s}^{-1}$.

Note que a variação dos recobrimentos não obedece a uma tendência geral, tornando a análise longe de ser trivial, Figura 17a. Neste sentido, a adoção do recobrimento total médio invariante ao tempo indica uma simplificação válida ao analisar as derivadas na Equação 5.2.3.6. Os resultados calculados na Figura 17 a corroboram com a observação experimental relatada por Osawa e colaboradores ${ }^{[49]}$ em que o aumento da densidade de corrente resultou no aumento e a diminuição da intensidade de banda de formato e monóxido de carbono linear, respectivamente. Utilizando-se das relações obtidas através da Equação 5.2.3.6 e das simulações via Figura 17b, a identificação do sinal da primeira e terceira derivada é direta, 


$$
\left(\frac{\partial P_{U}}{\partial \theta_{t}^{m}}\right)_{j_{t}}>0 \quad e\left(\frac{\partial j_{t}}{\partial T}\right)_{\theta_{t}^{m}}>0
$$

onde o sinal positivo na primeira derivada obedece à observações experimentais e teóricas, vide Figura 14a e 15a. Correntes baixas resultam em oscilações mais lentas ou com maior período enquanto que correntes altas o período decresce. Portanto, com base na Figura 17b, o aumento do recobrimento total médio aumenta para correntes baixas que implica em períodos maiores. A segunda relação obedece à equação usual de Arrhenius em que o aumento da temperatura resulta no aumento da corrente total, dado um recobrimento médio total constante.

Em regime oscilatório, o sinal da energia de ativação global da reação é obtido pelos valores de $q_{10}$ (e.g. Tabela II), logo,

$$
\begin{array}{r}
\text { baixas } j_{t}: q_{10}<1 \Rightarrow E_{a}^{t}<0 \\
\text { altas } j_{t}: q_{10} \rightarrow 1 \Rightarrow E_{a}^{t} \rightarrow 0
\end{array}
$$

assim, é possível obter através das simulações, vide Figura 17b,

$$
\begin{gathered}
\text { baixas } j_{t}:\left(\frac{\partial \theta_{t}^{m}}{\partial j_{t}}\right)_{T}<0 \Rightarrow \frac{\partial \ln P_{U}}{\partial T}>0 \\
\text { altas } j_{t}:\left(\frac{\partial \theta_{t}^{m}}{\partial j_{t}}\right)_{T} \rightarrow 0 \Rightarrow \frac{\partial \ln P_{U}}{\partial T} \rightarrow 0
\end{gathered}
$$

Note que em (a) baixas correntes aplicadas um aumento da temperatura resultou em um aumento do período oscilatório e (b) altas correntes aplicadas o período permaneceu 
ligeiramente independente da temperatura. Exatamente como observado experimentalmente e através de simulações numéricas. O resultado indica que o recobrimento total (ou sítios vacantes) possui papel decisivo no período oscilatório. Considerando, portanto, o recobrimento total como uma combinação linear dos recobrimentos de todas as espécies adsorvidas na superfície metálica, é evidente, vide Figura 17a, que embora exista o aumento de $\theta_{H C O O}{ }^{m}, \theta_{O H}{ }^{m}$, a variação do recobrimento total médio é governado pela diminuição de $\theta_{C O L}{ }^{m}$. Este resultado, está plenamente de acordo com as conclusões sugeridas por Carbonio et $a l .{ }^{[73]}$ em que a diferença da influência da temperatura na dinâmica oscilatória de metanol e ácido fórmico é causada pelas reações de construção/remoção do recobrimento de monóxido de carbono em regime oscilatório. Com base nos resultados experimentais e teóricos é evidente que o comportamento de (sobre)compensação de temperatura durante a EAF é um fenômeno puramente superficial. Entretanto, não é possível assumir apenas a taxa de construção/remoção do recobrimento de $\mathrm{CO}_{\mathrm{L}}$ como a etapa elementar governante do período devido às grandes diferenças entre as energias de ativação obtidas em regime oscilatório durante a EAF e EOM. Ademais, observa-se que em altas correntes a variação do recobrimento total torna-se mais dependente dos recobrimentos de $\mathrm{HCOO}_{\mathrm{ad}}$ e $\mathrm{OH}_{\mathrm{ad}}$, vide Figura 17b. Neste caso, o período deve ser governado pelo acoplamento de pelo menos duas etapas reacionais, como a formação/remoção dos recobrimentos de $\mathrm{CO}_{\mathrm{L}}$ e $\mathrm{HCOO}_{\mathrm{ad}}$. A justificativa é embasada em situações de alta corrente aplicada onde são observadas oscilações rápidas ou de altas freqüências. Neste caso, o recobrimento de monóxido de carbono encontrado experimentalmente gira em torno de $\theta_{C O L} \sim 0,1^{[49]}$ o que indica que o recobrimento de $\mathrm{CO}_{\mathrm{L}}$ não é o único responsável pelo aumento de $\varphi_{D L}$ na etapa $(2 \rightarrow 3)$. Corroborando com este cenário, Chen et al. ${ }^{[53]}$ mostraram, por meio de experimentos cronoamperométricos com pré-polarização em $1,20 \mathrm{~V}$, que a velocidade de formação de $\mathrm{CO}_{\mathrm{L}}$ entre 0,50 e 0,60 V é menor em comparação à formação de $\mathrm{CO}_{\mathrm{B}}$ e $\mathrm{HCOO}_{\mathrm{ad}}$. Neste caso, o 
recobrimento de $\mathrm{CO}_{\mathrm{L}}$ não atingiu a saturação superficial em tempo menor que 2 minutos para temperaturas entre 25 à $60^{\circ} \mathrm{C}$, enquanto que formato a saturação ocorreu em escala de segundos (i.e na ordem de 1 segundo, resolução empregada para os experimentos cronoamperométricos). Energias de ativação para o processo de desidratação do ácido fórmico em torno de 73 e $117 \mathrm{~kJ} \mathrm{~mol}^{-1}$ foram obtidos experimentalmente nos potenciais em 0,50 e $0,60 \mathrm{~V}$, respectivamente ${ }^{[53]}$. No entanto, a formação de $\mathrm{CO}_{\mathrm{L}}$ tende a aumentar de maneira considerável com o aumento da temperatura, provocando a diminuição da intensidade de banda de formato. Neste sentido, é importante salientar a influência de $\mathrm{CO}_{\mathrm{L}}$ em relação à força de adsorção de outras espécies, onde: $\mathrm{CO}_{\mathrm{ad}}>\mathrm{HCOO}_{\mathrm{ad}}>(\mathrm{H}) \mathrm{SO}_{4}{ }^{-}>\left(\mathrm{H}_{\mathrm{x}}\right) \mathrm{O}_{\mathrm{ad}}$. Se a velocidade da reação (r3) fosse responsável majoritário pelo aumento do potencial da dupla camada, favorecendo o aumento da cobertura de $\mathrm{CO}_{\mathrm{L}}$ na etapa $(2 \rightarrow 3)$ era esperado que com o aumento da temperatura o período oscilatório decrescesse, tal comportamento não foi observado. Embasando-se nas informações experimentais dada acima, acredita-se que o recobrimento de $\mathrm{CO}_{\mathrm{L}}$ tenha um papel secundário na via reacional que governa o período. Considerando a via direta como a etapa dominante e a decomposição de formato como a etapa lenta da reação, acredita-se que a via reacional (r2) é responsável pela variação do tamanho do período oscilatório. Neste sentido, observações teóricas neste trabalho, identificam a relação entre o aumento da frequiência oscilatória com o aumento da velocidade de decomposição de formato, $\mathrm{v}_{2}{ }^{\mathrm{m}}$, Figura $17 \mathrm{~b}$. Portanto, a explicação mecanística para o comportamento antiArrhenius é dada como segue. Em (a) baixas correntes aplicadas: o aumento da temperatura resulta no aumento do recobrimento de monóxido de carbono que por sua vez inibi a decomposição de formato por meio da ocupação de sítios vacantes. Embora, exista um maior recobrimento de $\mathrm{CO}_{\mathrm{L}}$ sua taxa de formação $\left(k_{3}=1.10^{2} \mathrm{~L} \mathrm{~mol}^{-1} \mathrm{~s}^{-1}\right.$ à $\left.25^{\circ} \mathrm{C}\right)$ é muito lenta em relação à formação de $\mathrm{HCOO}_{\mathrm{ad}}\left(k_{l}{ }^{\prime}=50,8 \cdot 10^{6} \mathrm{~L} \mathrm{~mol}^{-1} \mathrm{~s}^{-1}\right.$ em $\varphi_{D L}=0,50 \mathrm{~V}$ à $\left.25^{\circ} \mathrm{C}\right)$. Neste caso, o aumento do potencial da dupla camada está diretamente relacionado com o aumento 
do recobrimento superficial de formato. Assim, como o aumento da temperatura prejudica a via da reação (r1), espera-se o aumento do período oscilatório. Note que em oscilações mais lentas, observam-se maiores amplitudes (i.e. aproximadamente 0,30 V). Esta relação está ligada ao favorecimento do recobrimento de $\mathrm{CO}_{\mathrm{L}}$ que por sua vez é removido na etapa $(3 \rightarrow$ 4) (i.e. região da NDR), em potencial próximo ou acima de $0,80 \mathrm{~V}$, promovendo o processo de reativação superficial, vide Figura 12. Em (b) altas correntes aplicadas: nesta condição a variação do recobrimento médio total é muito pequeno o que indica um baixo recobrimento de $\mathrm{CO}_{\mathrm{L}}$ (i.e. próximo de $0,1^{[49]}$ ). Espera-se que com o aumento da temperatura, a taxa de formação de $\mathrm{CO}_{\mathrm{L}}$ seja insignificante em relação à formação de $\mathrm{HCOO}_{\mathrm{ad}}$. Assim, considerando a pequena influência do recobrimento de $\mathrm{CO}_{\mathrm{L}}$, a etapa $(2 \rightarrow 3)$ é regida de forma majoritária pela formação/remoção do recobrimento de formato. Esta afirmação justifica também as pequenas amplitudes (i.e. em torno de 0,20 V) observadas experimentalmente, vide Figura 13, em que o potencial não atingiu valores acima de $0,80 \mathrm{~V}$ e, portanto, a NDR foi ocasionada exclusivamente pela adsorção deliberada de $\mathrm{HCOO}_{\mathrm{ad}}$. 


\section{ConClusões}

Resultados experimentais do impacto da temperatura durante a EAF sobre platina policristalina em meio ácido em regime oscilatório revelaram características únicas. Energia de ativação aparentes estimadas em condições voltamétricas durante varredura lenta de $5 \mathrm{mV}$ $\mathrm{s}^{-1}$, foram encontradas no intervalo de 50 à $80 \mathrm{~kJ} \mathrm{~mol}^{-1}$. Em contraste, sob condições oscilatórias, apenas comportamento anti-Arrhenius foi observado (i.e. sobre-compensação e compensação de temperatura) onde período e amplitude oscilatória mostraram-se altamente dependentes da temperatura e densidade de corrente aplicada. De modo geral, foi observado que em (a) baixas correntes aplicadas um aumento da temperatura resultou em um aumento do período e amplitude e (b) altas correntes aplicadas ambos, período e amplitude foram ligeiramente independentes da temperatura. A alta energia de ativação aparente obtida sob condições voltamétricas, não oscilatórias, demonstrou que o comportamento anti-Arrhenius observado em modo oscilatório resulta do acoplamento entre diferentes etapas reacionais em vez de uma fraca dependência das etapas elementares com a temperatura.

Sob o ponto de vista teórico, a inclusão da etapa de formação das espécies oxigenadas e formato como intermediário ativo foram essenciais para o aparecimento do comportamento de (sobre)compensação de temperatura. O modelo proposto capturou as características essenciais da EAF sobre platina policristalina, quantificando de forma aceitável os valores apresentados pelas variáveis dinâmicas. Neste sentido, indicou o acoplamento entre a formação/remoção dos recobrimentos de $\mathrm{CO}_{\mathrm{L}}$ e $\mathrm{HCOO}_{\mathrm{ad}}$ como as vias dominantes e regentes do período oscilatório. 


\section{Perspectivas}

A identificação das etapas elementares responsáveis pelo controle do período oscilatório pode ser facilmente obtida pelo conceito do balanço antagônico. Neste sentido, o período oscilatório é dependente da temperatura como função das constantes de velocidades das $N$ etapas pertencentes ao sistema,

$$
P:=f\left(k_{1}, k_{2}, \ldots, k_{N}\right)
$$

Note que $N$ representa a soma entre as etapas que favorecem o decréscimo do período, $n$ (i.e. ciclo de retro-alimentação positivo) e as que aumentam o período, $m$ (i.e. ciclo de retroalimentação negativo). Portanto, a dependência do período oscilatório com a temperatura pode ser escrita como,

$$
\frac{\partial P}{\partial T}=\frac{f}{R T^{2}} \sum_{i=1}^{n+m} \frac{\partial \ln f}{\partial \ln k_{i}} E_{a}^{i}
$$

o controle regulatório torna-se evidente após a separação algébrica,

$$
\frac{\partial P}{\partial T}=\frac{f}{R T^{2}}\left(\sum_{i_{P}(-)}^{n} b_{i} E_{a}^{i}+\sum_{j_{P(+)}}^{m} b_{j} E_{a}^{j}\right) ; \quad \text { onde } b=\frac{\partial \ln f}{\partial \ln k}
$$

Sabendo-se que $b_{i}<0, b_{j}>0$ e as energias de ativação das etapas elementares são sempre positivas, o comportamento de sobre-compensação de temperatura é atingido quando as reações que compõem o ciclo de retro-alimentação negativo são dominantes na regulação 
do período oscilatório em relação às reações pertencentes ao ciclo de retro-alimentação positivo, logo $\partial \mathrm{P} / \partial \mathrm{T}>0$. Para o caso de compensação de temperatura, os ciclos de retroalimentação positivo e negativo possuem a mesma magnitude o que resulta em $\partial \mathrm{P} / \partial \mathrm{T}=0$.

No entanto, para o controle do balanço antagônico torna-se necessário o refinamento do modelo apresentado na seção 4. O comportamento de (sobre)compensação de temperatura durante a EAF foi obtido qualitativamente com êxito, desprezando-se o efeito da temperatura nas constantes cinéticas de velocidade das etapas químicas, $k_{i}$ e $k_{-i}$. Esta condição de contorno é uma simplificação de caráter não usual devido às diversas observações experimentais da dependência exponencial de $k$ em função de $T$. Neste sentido, a equação de Arrhenius será incorporada no modelo genérico com a finalidade de tornar-lo mais realista possível, logo,

$$
\begin{gathered}
k_{i}^{\prime}=A_{i} \exp \left(-\frac{E_{a}^{i}}{R T}\right) \exp \left[\frac{\alpha_{i} n F \varphi_{D L}}{R T}\right] ; \\
k_{-i}^{\prime}=A_{-i} \exp \left(-\frac{E_{a}^{-i}}{R T}\right) \exp \left[\frac{-\left(1-\alpha_{i}\right) n F \varphi_{D L}}{R T}\right]
\end{gathered}
$$

Note que a inclusão da energia de ativação nas etapas eletroquímicas torna o modelo fisicamente mais aceitável, tornando possível a manipulação pelo balanço antagônico. Desse modo, pode-se generalizar uma energia de ativação total via uma função $\Psi$ dependente da energia de ativação da etapa química e do coeficiente de transferência da etapa eletroquímica,

$$
\Psi_{i}\left(\varphi_{D L}\right)=\frac{1}{R T}\left(\alpha_{i} n F \varphi_{D L}-E_{a}^{i}\right) ; \quad \Psi_{-i}\left(\varphi_{D L}\right)=\frac{1}{R T}\left[-\left(1-\alpha_{i}\right) n F \varphi_{D L}-E_{a}^{-i}\right]
$$

onde $A$ é o fator pré-exponencial independente da temperatura e $\Psi$ quantifica a "barreira" energética total da etapa elementar, tanto para a via anódica $\Psi_{i}$, quanto para a via catódica $\Psi_{-i}$. 


\section{REFERÊNCIAS BIBLIOGRÁFICAS}

1. Nicolis, G.; Prigogine, I. Exploring Complexity: An Introduction. New York :W. H. Freeman and Company, 1989.

2. Taylor, A. F. Mechanism and Phenomenology of an Oscillating Chemical Reaction. Progress in Reaction Kinetics and Mechanism, v. 27, n. 4, p. 247-325, 2002.

3. Imbihl, R.; Ertl, G. Oscillatory Kinetics in Heterogeneous Catalysis. Chemical Reviews, v. 95, n. 3, p. 697-733, 1995.

4. Wojtowicz, J. Oscillatory Behaviour in Electrochemical Systems. In Modern Aspects of Electrochemistry, Conway, B. E.; Bockris, J.; White, R. New York: Kluver Academic/Plenum Publishers, v. 8, 1973.

5. Hudson, J. L.; Tsotsis, T. T. Electrochemical Reaction Dynamics - A Review. Chemical Engineering Science, v. 49, n. 10, p. 1493-1572, 1994.

6. Koper, M. T. M. Oscillations and Complex Dynamical Bifurcations in Electrochemical Systems. In Advances in Chemical Physics, Prigogine, I.; Rice, S. A. New York: Wiley, v. 92, p. 161, 1996.

7. Krischer, K. Principles of Spatial and Temporal Pattern Formation in Electrochemical Systems. In Modern Aspects of Electrochemistry, Conway, B. E.; Bockris, J.; White, R.

New York: Kluver Academic/Plenum Publishers, v. 32, p. 1, 1999.

8. Krischer, K.; Varela, H. Oscillations and Other Dynamic Instabilities. In Handbook of Fuel Cells: Fundamentals, Technology, Applications., Vielstich, W.; Gasteiger, H. A.; Lamm, A. Chichester: John Wiley \& Sons, v. 2, p. 679, 2003.

9. Guerasimov, Y. A.; Dreving, V.; Eriomin, E.; Kiseliov, A.; Lebedev, V.; Panchekov, G.; Shliguin, A. Curso de Química Física. 2a ed.; Morcu: Mir, 1971.

10. Glasstone, S. Textbook of Physical Chemistry. London: Macmillan and Co. Limited, 1962. 
11. Ruoff, P.; Loros, J. J.; Dunlap, J. C. The Relationship Between FRQ-protein Stability and Temperature Compensation in the Neurospora Circadian Clock. Proceedings of the National Academy of Sciences of the United States of America, v. 102, n. 49, p. 1768117686, 2005.

12. Glass, L.; Mackey, M. C. From Clock to Chaos: The Rhythms of Life. Princeton: Princeton University Press, 1988.

13. Pittendrigh, C. S. Temporal Organization - Reflections of a Darwinian Clock-Watcher. Annual Review of Physiology, v. 55, p. 16-54, 1993.

14. Iwasaki, K.; Liu, D. W. C.; Thomas, J. H. Genes that Control a TemperatureCompensated Ultradian Clock in Caenorhabditis-Elegans. Proceedings of the National Academy of Sciences of the United States of America, v. 92, n. 22, p. 10317-10321, 1995.

15. Ruoff, P.; Rensing, L. Temperature Effects on Circadian Clocks, International Thermal Physiology Symposium, Greece: Pergamon-Elsevier Science Ltd, p. 445-456, 2004.

16. Ruoff, P.; Vinsjevik, M.; Rensing, L. Temperature Compensation in Biological Oscillators: A Challenge for Joint Experimental and Theoretical Analysis. Comments on Theoretical Biology, 2000.

17. Mozurkewich, M.; Benson, S. W. Negative Activation-Energies and Curved Arrhenius Plots.1. Theory of Reactions Over Potentail Wells. Journal of Physical Chemistry, v. 88, n. 25, p. 6429-6435, 1984.

18. Mozurkewich, M.; Lamb, J. J.; Benson, S. W. Negative Activation-Energies and Curved Arrhenius Plots.2. OH + CO. Journal of Physical Chemistry, v. 88, n. 25, p. 64356441, 1984.

19. Lamb, J. J.; Mozurkewich, M.; Benson, S. W. Negative Activation-Energies and Curved Arrhenius Plots.3. $\mathrm{OH}+\mathrm{HNO}_{3}^{-}$and $\mathrm{OH}+\mathrm{HNO}_{4}^{-}$. Journal of Physical Chemistry, v. 88, n. 25, p. 6441-6448, 1984.

20. Ruoff, P. Introducing Temperature-Compensation in Any Reaction Kinetic Oscillator Model. Journal of Interdisciplinary Cycle Research, v. 23, n. 2, p. 92-99, 1992. 
21. Ruoff, P. General Homeostasis in Period-Compensated and TemperatureCompensated Chemical Clock Mutants Formed by Random Selection Conditions. Naturwissenschaften, v. 81, n. 10, p. 456-459, 1994.

22. Huang, Z. J.; Curtin, K. D.; Rosbash, M. PER Protein Interactions and Temperature Compensation of a Circadian Clock in Drosophila. Science, v. 267, p. 1169-1172, 1995.

23. Somero, G. N.; Low, P. S. Eurytolerant Proteins - Mechanisms for Extending Enviromental Tolerance Range of Enzyme-Ligand Interactions. American Naturalist, v. 111, n. 979 , p. 527-538, 1977.

24. Müller, S. C.; Hauser, M. J. B. Patterns and Waves in Chemistry and Biology. In Handbook of Biomimetics, Osaka, Y.; Kai, S.; Kakasu, Y.; Kataoka, K.; Sakai, K.; Tanaka, J. Tokyo: NTS Books, p. 87, 2000.

25. Lillie, R. S. Transmission of Activation in Passive Metals as a Model of the Protoplasmic or Nervous type of Transmission. Science, v. 48, p. 51-60, 1918.

26. Keizer, J.; Rock, P. A.; Lin, S. W. Analysis of the Oscillations in Beating Mercury Heart Systems. Journal of the American Chemical Society, v. 101, n. 19, p. 5637-5649, 1979.

27. Zaikin, A. N.; Zhabotinsky, A. M. Concentration Wave Propagation in Twodimensional Liquid-phase Self-oscillating System. Nature, v. 225, p. 535-537, 1970.

28. Köros, E. Monomolecular Treatment of Chemical Oscillation. Nature, v. 251, p. 703704, 1974.

29. Ruoff, P. Antagonistic Balance in the Oregonator - About the Possibility of Temperature-Compensation in the Belousov-Zhabotinsky Reaction. Physica D, v. 84, p. 204$211,1995$.

30. Blandamer, M. J.; Morris, S. H. Investigation into Effect of Temperature and Added Tert-Butyl Alcohol on Dynamic Properties of Belousov Reaction. Journal of the Chemical Society-Faraday Transactions I, v. 71, p. 2319-2330, 1975.

31. Cervellati, R.; Furrow, S. D.; De Pompeis, S. Benzylmalonic Acid Reaction with Iodine and Behavior in a Briggs-Rauscher Oscillator. International Journal of Chemical Kinetics, v. 34, n. 6, p. 357-365, 2002. 
32. Cervellati, R.; Honer, K.; Furrow, S. D.; Mazzanti, F.; Costa, S. An Experimental and Mechanistic Investigation of the Complexities Arising During Inhibition of the BriggsRauscher Reaction by Antioxidants. Helvetica Chimica Acta, v. 87, n. 1, p. 133-155, 2004.

33. Kereszturi, K.; Szalai, I. Briggs-Rauscher Reaction with 1,4-cyclohexanedione Substrate. Zeitschrift Fur Physikalische Chemie-International Journal of Research in Physical Chemistry \& Chemical Physics, v. 220, n. 8, p. 1071-1082, 2006.

34. Rábai, G.; Hanazaki, I. Temperature Compensation in the Oscillatory Hydrogen Peroxide-Thiosulfate-Sulfite Flow System. Chemical Communications, v. 19, p. 1965-1966, 1999.

35. Kovács, K. M.; Rábai, G. Temperature-Compensation in pH-Oscillators. Physical Chemistry Chemical Physics, v. 4, n. 21, p. 5265-5269, 2002.

36. Kovács, K.; Hussami, L. L.; Rábai, G. Temperature Compensation in the Oscillatory Bray Reaction. Journal of Physical Chemistry A, v. 109, n. 45, p. 10302-10306, 2005.

37. Koper, M. T. M.; Sluyters, J. H. Electrochemical Oscillators - Their Description Through a Mathematical Model. Journal of Electroanalytical Chemistry, v. 303, v. 1-2, p. 73-94, 1991.

38. Strasser, P.; Eiswirth, M.; Koper, M. T. M. Mechanistic Classification of Electrochemical Oscillators - Operational Experimental Strategy. Journal of Electroanalytical Chemistry, v. 478, n. 1-2, p. 50-66, 1999.

39. Koper, M. T. M.; Gaspard, P. The Modeling of Mixed-Mode and Chaotic Oscillations in Electrochemical Systems. Journal of Chemical Physics, v. 96, n. 10, p. 7797-7813, 1992.

40. Koper, M. T. M. The Theory of Electrochemical Instabilities. Electrochimica Acta, v. 37, n. 10, p. 1771-1778, 1992.

41. Koper, M. T. M.; Sluyters, J. H. Electrochemical Oscillators - An Experimental Study of the Indium Thiocyanate Oscillator. Journal of Electroanalytical Chemistry, v. 303, n. 12, p. 65-72, 1991.

42. Strogatz, S. H. Nonlinear Dynamics and Chaos: With Applications to Physics, Biology, Chemistry and Engineering. Cambridge: Addison-Wesley, 1994. 
43. Hilborn, R. C. Chaos and Nonlinear Dynamics. New York: Oxford Press, 2000.

44. Vielstich, W. Fuel Cells. Bristol: Wiley Interscience, 1965.

45. Markovic, N. M.; Ross, P. N. Surface Science Studies of Model Fuel Cell Electrocatalysts. Surface Science Reports, v. 45, p. 117-229, 2002.

46. Capon, A.; Parsons, R. Oxidation of Formic Acid at Noble Metal Electrodes.1. Review of Previous Work. Journal of Electroanalytical Chemistry, v. 44, n. 1, p. 1-7, 1973.

47. Capon, A.; Parsons, R. Oxidation of Formic Acid at Noble Metal Electrodes.2. Comparison of Behavior of Pure Electrodes. Journal of Electroanalytical Chemistry, v. 44, n. 2, p. 239-254, 1973.

48. Capon, A.; Parsons, R. Oxidation of Formic Acid at Noble Metal Electrodes.3 Intermediates and Mechanism on Platinum Electrodes. Journal of Electroanalytical Chemistry, v. 45, n. 2, p. 205-231, 1973.

49. Samjeské, G.; Miki, A.; Ye, S.; Yamakata, A.; Mukouyama, Y.; Okamoto, H.; Osawa, M. Potential Oscillations in Galvanostatic Electrooxidation of Formic Acid on Platinum: A Time-Resolved Surface-Enhanced Infrared Study. Journal of Physical Chemistry B, v. 109, n. 49, p. 23509-23516, 2005.

50. Samjeské, G.; Osawa, M. Current Oscillations During Formic Acid Oxidation on a Pt Electrode: Insight into the Mechanism by Time-Resolved IR Spectroscopy. Angewandte Chemie, v. 44, n. 35, p. 5694-5698, 2005.

51. Samjeské, G.; Miki, A.; Ye, S.; Osawa, M. Mechanistic Study of Electrocatalytic Oxidation of Formic Acid at Platinum in Acidic Solution by Time-Resolved SurfaceEnhanced Infrared Absorption Spectroscopy. Journal of Physical Chemistry B, v. 110, n. 33, p. 16559-16566, 2006.

52. Mukouyama, Y.; Kikuchi, M.; Samjeské, G.; Osawa, M.; Okamoto, H. Potential Oscillations in Galvanostatic Electrooxidation of Formic Acid on Platinum: A Mathematical Modeling and Simulation. Journal of Physical Chemistry B, v. 110, n. 24, p. 11912-11917, 2006. 
53. Chen, Y. X.; Ye, S.; Heinen, M.; Jusys, Z.; Osawa, M.; Behm, R. J. Application of insitu Attenuated Total Reflection-Fourier Transform Infrared Spectroscopy for the Understanding of Complex Reaction Mechanism and Kinetics: Formic Acid Oxidation on a Pt Film Electrode at Elevated Temperatures. Journal of Physical Chemistry B, v. 110, n. 19, p. 9534-9544, 2006.

54. Chen, Y. X.; Heinen, M.; Jusys, Z.; Behm, R. J. Bridge-Bonded Formte: Active Intermediate or Spectator Species in Formic Acid Oxidation on a Pt Film Electrode? Langmuir, v. 22, n. 25, p. 10399-10408, 2006.

55. Chen, Y. X.; Miki, A.; Ye, S.; Sakai, H.; Osawa, M. Formate, an Active Intermediate for Firect oxidation of Methanol on Pt Electrode. Journal of the American Chemical Society, v. 125, n. 13, p. 3680-3681, 2003.

56. Samjeské, G.; Miki, A.; Osawa, M. Electrocatalytic Oxidation of Formaldehyde on Platinum under Galvanostatic and Potential Sweep Conditions Studied by Time-Resolved Surface-Enhanced Infrared Spectroscopy. Journal of Physical Chemistry C, v. 111, n. 41, p. 15074-15083, 2007.

57. Falconer, J. L.; Madix, R. J. Kinetics and Mechanism of Autocatalytic Decomposition of HCOOH on Clean Ni(110). Surface Science, v. 46, n. 2, p. 473-504, 1974.

58. Conway, B. E. Electrochemical Oxide Film Formation at Noble Metals as a SurfaceChemical Process. Progress in Surface Science, v. 49, p. 331-452, 1995.

59. Albahadily, F. N.; Schell, M. Observation of Several Different Temporal Patterns in the Oxidation of Formic Acid at a Rotating Platinum Disk Electrode in an Acidic Medium. Journal of Electroanalytical Chemistry, v. 308, n. 1-2, p. 151-173, 1991.

60. Strasser, P.; Eiswirth, M.; Ertl, G. Oscillatory Instabilities During Formic Acid Oxidation on $\mathrm{Pt}(100), \mathrm{Pt}(110)$ and $\mathrm{Pt}(111)$ under Potentiostatic Control .2. Model Calculations. Journal of Chemical Physics, v. 107, n. 3, p. 991-1003, 1997.

61. Okamoto, H.; Tanaka, N.; Naito, M. Modelling Temporal Kinetic Oscillations for Electrochemical Oxidation of Formic Acid on Pt. Chemical Physics Letters, v. 248, n. 3-4, p. 289-295, 1996.

62. Batista, B. C.; Sitta, E.; Eiswirth, M.; Varela, H. Autocatalysis in the Open Circuit Interaction of Alcohol Molecules with Oxidized Pt Surfaces. Physical Chemistry Chemical Physics, v. 10, n. 44, p. 6686-6692, 2008. 
63. Bard, A. J.; Faulkner, L. R. Electrochemical Methods: Fundamentals and Applications. New York: John Wiley \& Sons, 1980.

64. Nagao, R. Auto-organização Temporal na Interface Sólido/Líquido: Eletrooxidação de Ácido Fórmico sobre Platina. Universidade de São Paulo, São Carlos, 2006.

65. Strasser, P.; Lubke, M.; Raspel, F.; Eiswirth, M.; Ertl, G. Oscillatory Instabilities during Formic Acid Oxidation on $\mathrm{Pt}(100), \mathrm{Pt}(110)$ and $\mathrm{Pt}(111)$ under Potentiostatic Control .1. Experimental. Journal of Chemical Physics, v. 107, n. 3, p. 979-990, 1997.

66. Varela, H.; Krischer, K. Nonlinear Phenomena during Electrochemical Oxidation of Hydrogen on Platinum Electrodes. Catalysis Today, v. 70, p. 411-425, 2001.

67. Zhang, J. X.; Datta, R. Sustained Potential Oscillations in Proton Exchange Membrane Fuel Cells with PtRu as Anode Catalyst. Journal of the Electrochemical Society, v. 149, n. 11, p. A1423-A1431, 2002.

68. Cohen, J. L.; Volpe, D. J.; Abruña, H. D. Electrochemical Determination of Activation Energies for Methanol Oxidation on Polycrystalline Platinum in Acidic and Alkaline Electrolytes. Physical Chemistry Chemical Physics, v. 9, n. 1, p. 49-77, 2007.

69. Lakin-Thomas, P. I.; Brody, S.; Cote, G. G. Amplitude Model for the Effects of Mutations and Temperature on Period and Phase Resetting of the Neurospora Circadian Oscillator. Journal of Biological Rhythms, v. 6, n. 4, p. 281-297, 1991.

70. Liu, Y.; Merrow, M.; Loros, J. J.; C., D. J. How Temperature Changes Reset a Circadian Oscillator. Science, v. 281, p. 825-829, 1998.

71. Pittendrigh, C. S.; Kyner, W. T.; Takamura, T. The Amplitude of Circadian Oscillations - Temperature Dependence, Latitudinal Clines, and the Photoperiodic Time Measurement. Journal of Biological Rhythms, v. 6, n. 4, p. 299-313, 1991.

72. Nagy, G.; Koros, E.; Oftedal, N.; Tjelflaat, K.; Ruoff, P. Effect of Temperature in Cerium-Ion-Catalyzed Bromate-Driven Oscillators. Chemical Physics Letters, v. 250, n. 3-4, p. 255-260, 1996.

73. Carbonio, E. A.; Nagao, R.; Gonzalez, E. R.; Varela, H. Temperature Effects on the Oscillatory Electro-oxidation of Methanol on Platinum. Physical Chemistry Chemical Physics, v. 11, p. 665-670, 2009. 
74. Martins, A. L.; Batista, B. C.; Sitta, E.; Varela, H. Oscillatory Instabilities during the Electrocatalytic Oxidation of Methanol on Platinum. Journal of the Brazilian Chemical Society, v. 19, p. 679-687, 2008.

75. Siegmeier, J.; Baba, N.; Krischer, K. Bistability and Oscillations During Electrooxidation of $\mathrm{H}_{2}-\mathrm{CO}$ Mixtures on Pt: Modeling and Bifurcation Analysis. Journal of Physical Chemistry C, v. 111, n. 36, p. 13481-13489, 2007.

76. Nagao, R.; Epstein, I. R.; Gonzalez, E. R.; Varela, H. Temperature (Over)compensation in an Oscillatory Surface Reaction. Journal of Physical Chemistry A, v. 112, n. 20, p. 4617-4624, 2008. 
ANEXOS 